\title{
NRSIR 82-2497
}

\begin{tabular}{l} 
Procedure for Determining \\
Annual Efficiency for Vented \\
Household Heaters and Furnaces \\
Equipped With Modulating-Type \\
Controls \\
\hline
\end{tabular}

U.S. DEPARTMENT OF COMMERCE

National Bureau of Standards

National Engineering Laboratory

Center for Building Technology

Building Equipment Division

Washington, DC 20234

May 1982

Prepared for:

Jited States Department of Energy

ashington, DC 20585 

A TEST METHOD AND CALCULATION PROCEDURE FOR DETERMINING ANNUAL EFFICIENCY FOR VENTED HOUSEHOLD HEATERS AND FURNACES EQUIPPED WITH MODULATING-TYPE CONTROLS

Esher Kweller

Robert L. Palla, Jr.

U.S. DEPARTMENT OF COMMERCE

National Bureau of Standards

National Engineering Laboratory

Center for Building Technology

Building Equipment Division

Washington, DC 20234

May 1982

Prepared for:

United States Department of Energy

Washington, DC 20585

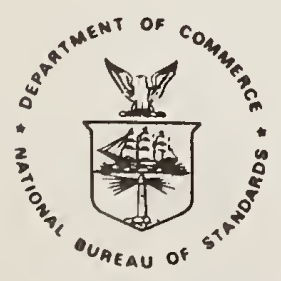

U.S. DEPARTMENT OF COMMERCE, Malcolm Baldrige, Secretary NATIONAL BUREAU OF STANDARDS, Ernest Ambler, Director 



\section{ABSTRACT}

As annual operating efficiency of vented heating equipment is affected by burner fuel and combustion air modulation, it is important to differentiate between the various types of controls in determining annual energy requirements. Test procedures for evaluating annual efficlency have already been developed and implemented by the Department of Energy (DoE) for furnaces with single-stage thermostat control. A modified test procedure is necessary to account for operation with fuel modulation. A revised procedure which accommodates two types of fuel modulating controls has recently been developed. Tests are conducted at reduced and maximum firing rates, and along with typical derived values, from a bin analysis of weather data, the fraction of the total hours for each operating mode is obtained to calculate a weighted annual efficiency. These test methods and calculation procedures are based on and are an extension to the current DoE test procedures for the single-stage type of thermostat control of central warm air furnaces.

By using the procedures developed in the report, the energy savings impact of fuel modulating controls when combined with the use of modulated combustion air is evaluated. Energy savings from 6 percent to 20 percent were determined from the increase in efficlency with both fuel and combustion air modulation. Improved efficlency was dependent on the type of thermostat control and the minimum-to-maximum fueled input; i.e., turndown ratio.

Key Words: annual efficlency; household heaters and furnace test procedures; hydraulic thermostat control; modulating control gas-fueled; two-stage thermostat. 
1. INTRODUCTION .................................... 1

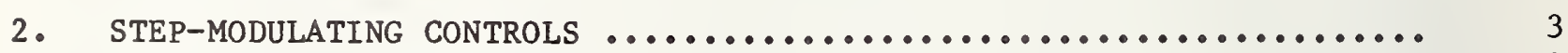

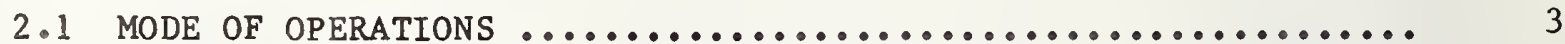

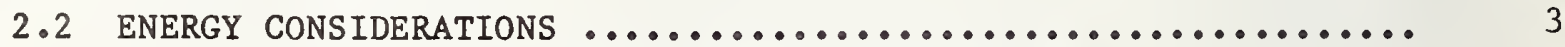

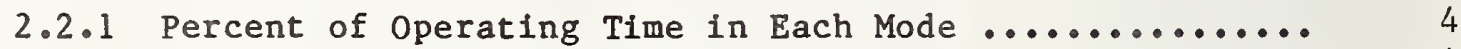

2.2.2 Average Outdoor Temperature in Each Mode ............. 4

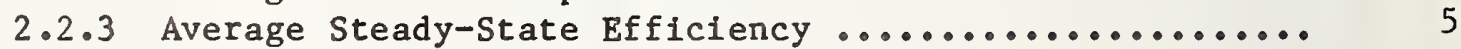

2.2.4 Infiltration Loss in the Modulating Mode ............. 6

3. TEST PROCEDURE AND CALCULATIONS ......................... 7

3.1 CURRENT TEST PROCEDURE ............................ 7

3.2 MEASUREMENTS AND CALCULATIONS FOR HEATERS WITH STEP-

MODULATING CONTROLS ............................ 8

3.3 CALCULATIONS FOR HEATERS WITH TWO-STAGE CONTROLS .......... 9

4. IMPACT OF MODULATING CONTROLS ON ENERGY CONSUMPTION ........... 10

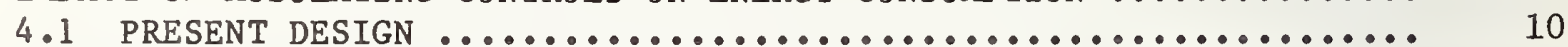

4.2 HEATERS EQUIPPED WITH THERMAL DAMPERS ................... 10

4.3 HEATERS WITH REDUCED COMBUSTION AIR AT REDUCED HEAT INPUT

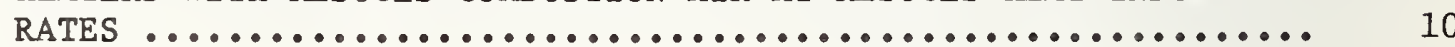

5. CONCLUSIONS $\ldots \ldots \ldots \ldots \ldots \ldots \ldots \ldots \ldots \ldots \ldots \ldots \ldots \ldots \ldots \ldots \ldots \ldots \ldots \ldots \ldots \ldots \ldots$

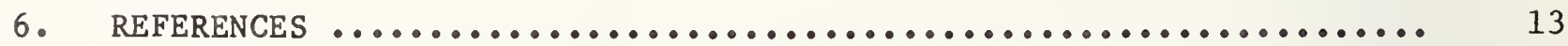

APPENDIX A - Determination of Outdoor Design Temperature for Vented

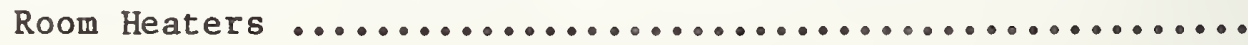

APPENDIX B - Detalled Calculation Procedure for Annual Efficiency of Heaters with Step-Modulating and Two-Stage Thermostat .....

APPENDIX C - Computer Program for the Evaluation of Annual Fuel Efficiency of Heating Equipment with Single-Stage, Two-Stage, and Step-Modulating Control 
Table 1. Development of Outdoor Temperatures and Time in Each Mode

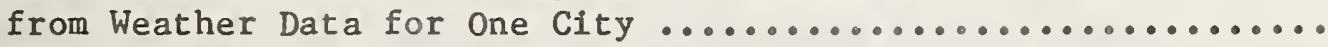

Table 2. Outdoor Temperatures and Time in Each Mode -- An Average of Eight Cities Having Total Heating Requirements of

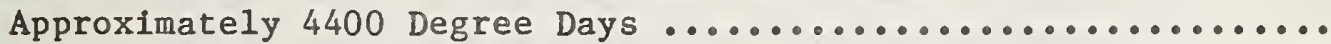

Table 3. Summary of Stack Losses and Efficiencies for a Room Heater

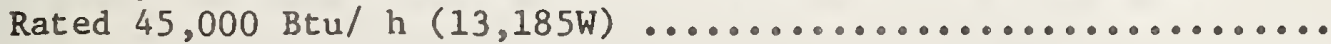

Table 4. Effect of Stack Damper and Operating Input Rate on the Stack (S) and Flue (F) Temperature and $\mathrm{CO}_{2}$ Values and Stack to Flue Mass Flow ( $/ F$ ) for Room Heater Rated 45,000 Btu/h $(13,185 \mathrm{~W}) \ldots$

Table 5. Effect of Type of Thermostat Control on Energy Saving Potential

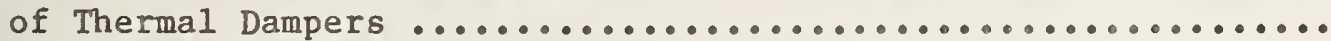

Table 6. Effect of Reduced Excess Combustion Air on Efficiency of a $35,000 \mathrm{Btu} / \mathrm{h}(10,255 \mathrm{~W})$ Room Heater Equipped with a

Step-Modulating Thermostat .........................

\section{LIST OF FIGURES}

Figure 1. Typical operating modes for heaters equipped with singlestage, two-stage, and step-modulating controls .............

Figure 2. Outlet gas pressure from a step-modulating thermostat control in response to changing room temperature .................

Figure 3. Part-load efficiency vs load for a heater with a stepmodulating control ...............................

Figure 4. Burner output rate vs heating load and associated outdoor temperature for a heater with step-modulating control .......

Figure 5. Balance point temperature (Tc) as a function of heater output ratio

Figure 6. Example of bin method used to determine percentage of time in cycling mode ....................................

Figure 7. Average outdoor temperature in cycling and non-cycling modes vs balance point temperature (Tc) ...................... 


\section{LIST OF FIGURES (Continued)}

Page

Figure 8. Average outdoor temperature and percent of time in cycling mode as a function of heater output ratio .................

Figure 9. The effect of burner fuel input rate on the part-1oad loss of a room heater with and without a thermal damper 
EFFYA

$\mathrm{L}_{\mathrm{I}, \mathrm{OFF}}$

LI, ON

$\mathrm{L}_{\mathrm{I}, \mathrm{ON}, \mathrm{min}}$

$\mathrm{L}_{\mathrm{I}, \mathrm{ON}, \max }$

$\mathrm{L}_{\mathrm{L}}$

$\mathrm{L}_{\mathrm{S}, \mathrm{OFF}}$

$\mathrm{L}_{\mathrm{S}, \mathrm{ON}}$

Ls, SS , A

PF

Qin

Qout

$Q_{P}$

$\mathrm{t}_{\mathrm{OFF}}$

$t_{\mathrm{ON}}$

$\mathrm{T}_{\mathrm{C}}$

Toa

$\mathrm{T}_{\text {oa' }}$

$\mathrm{T}_{\mathrm{RA}}$

$n_{\text {SS }}$
Annual Fuel Utilization Efficiency, in \%

off-cycle infiltration 1oss, in $\%$ of the fuel input rate On-cycle infiltration 1oss, in \% of the fuel input rate On-cycle infiltration loss, in $\%$ of the fuel input rate at minimum input rate

On-cycle infiltration loss, in $\%$ of the fuel input rate at maximum input rate

Latent heat loss, in $\%$ of the fuel input rate

off-cycle sensible heat 1oss, in $\%$ of the fuel input rate

On-cycle sensible heat loss, in \% of the fuel input rate

Sensible heat loss at steady-state operation, in $\%$ of the fuel input rate

Ratio of $Q_{P} \div Q_{i n}=$ pilot fraction

Fuel energy input rate at steady-state operation (including any pilot light input), in Btu/h, Qin,min at minimum input, $Q_{\text {in,max }}$ at maximum input rate.

Fuel energy output rate - Qout,min at minimum input rate, Qout,max at maximum input rate.

Fuel energy input rate to pilot light in Btu/h

off-time per cycle, in minutes

On-time per cycle, in minutes

Balance point outdoor air temperature

Average outdoor air temperature applicable to heater operation at minimum firing rate

Average outdoor air temperature applicable to heater operation between minimum and maximum rate

Laboratory room temperature, in ${ }^{\circ} \mathrm{F}$

Steady-state efficiency, in $\%$ of fuel input rate 


\begin{tabular}{|c|c|}
\hline$\eta_{u}$ & Part-load fuel utilization efficiency, in $\%$ \\
\hline$\alpha$ & Oversizing factor \\
\hline$n_{\text {ss, min }}$ & Steady-state efficiency at minimum input rate \\
\hline$n_{s s, \max }$ & Steady-state efficiency at maximum input rate \\
\hline$\eta_{\text {ss }}$, hi & $\begin{array}{l}\text { Average steady-state efficiency between minimum and maximum } \\
\text { input rates }\end{array}$ \\
\hline nss, wt & Weighted average steady-state efficiency \\
\hline$\eta_{\mu, \ell o}$ & Part load efficiency at the minimum input rate \\
\hline$n_{\mu, h i}$ & $\begin{array}{l}\text { Part load efficiency at the maximum input rate for two-stage } \\
\text { thermostats or for the non-cycling mode for step-modulating } \\
\text { thermostats }\end{array}$ \\
\hline$n_{\mu, W T}$ & Weighted part-load efficiency \\
\hline $\mathrm{R}_{10}$ & Percentage of operating time at the low input firing rate \\
\hline & Percentage of operating time in the non-cycling mode \\
\hline
\end{tabular}


As annual operating efficiency of vented heating equipment is affected by burner operating modes, it is important to differentiate between the various types of controls in determining annual energy requirements. Test procedures for evaluating annual efficiency have already been developed and implemented by the Department of Energy (DoE) for heaters with single-stage control [3]*. For two-stage and step-modulating units, however, a modified test procedure is necessary to account for operation at multiple firing rates. A revised procedure which accommodates modulating-type units has recently been developed and recommended to DoE $[1,2]$. A detailed review of the background for the recommendations of tests for modulating heaters in that procedure is the subject of this report.

Modulating controls investigated in this study are generally used with vented household heaters other than furnaces. However, the methods of test and the bin analysis procedures developed in this report for vented heaters are also applicable to central heating systems using the types of modulating controls described here. The only adjustment that would be needed to these procedures would be to use bin data based on the population of central furnaces in order to arrive at a national average annual efficiency specific to furnaces.

Three types of thermostatic controls are commonly used on automaticallycontrolled heating equipment. These are:

a. single-stage control, which cycles the heater between full input (100 percent of rating) and off;

b. two-stage control, which operates in an on-off cycling mode at either naximum input or at some reduced input which can be as 1 ow as 20 percent of maximum; and

c. step-modulating control, which steps on to a low input and then either cycles off and on at the low input if the heating load is light, or gradually increases the heat input to meet any higher heating load that cannot be met with the low firing rate.

Figure 1 illustrates the burner heat output rate and burner on periods (shaded) area) in response to increasing heating loads for each of these three types of controls.

The assumptions made in previous work [4] and as depicted by figure 1 that outdoor temperatures below $65^{\circ} \mathrm{F}$ would be directly proportional to heating load is valid only in a broad statistical sense. It should be understood that procedures developed here for calculating annual efficiency as well as current DoE test procedures for determining annual efficiency of the conventional type on-off thermostatically controlled heaters is intended for comparison purposes

* Numbers in brackets indicate references in section 6 . 
between equipment tested only under laboratory test conditions. A comprehensive treatment to include internal heat gains, solar radiation, wind, etc., would be needed in order to be valid for small time thermostatic cycling of the installed heating system. These procedures should not be considered as being predictive of the installed annual energy use. It should be understood that a comprehensive treatment of the building and furnace interaction to predict operating costs after installation is beyond the scope of this work. 


\subsection{MODE OF OPERATION}

One representation of the operating mode for the step-modulating type control is its response to room temperature (see figure 2 where room temperature and outlet gas pressure supplied to the burner from the thermostat control are shown).

Under normal operating conditions, as the ambient air temperature surrounding the liquid-filled thermostat sensing bulb drops to point $A$ on figure 2 , the control opens to allow minimum fuel flow (point B). When room air temperature rises to point $C$, the valve closes (point $D$ ). Operations on the $A B C D$ rectangle is termed the "cycling" mode.

If more severe weather is encountered while the valve is open to minimum flow (point B), room temperature may continue to drop until point $E$ is reached, at which time any further drop in room temperature would result in an increasing fuel flow. If the heating demand continues to increase with subsequent lower room temperature, fuel flow would gradually increase to maximum flow (from E to $G)$. In another situation, if the heating demand should just equal heater output for a prolonged time, the manifold could remain partially open (point $F$ or any other point between low fire and high fire) until the heating demand changes. Operation at the various firing rates from point $B$ to $G$ is termed the "noncycling" mode or modulating mode.

\subsection{ENERGY CONSIDERATIONS}

In developing test procedures for modulating type heaters, operation in both the cycling and non-cycling modes must be addressed. The importance of addressing both modes separately is apparent when one considers the difference in efficiency between the two modes as illustrated in figure 3. The part-load efficiency curve of figure 3 was plotted using data obtained with a room heater having a maximum rated input of $35,000 \mathrm{Btu} / \mathrm{h}$ and minimum adjusted input of $21,000 \mathrm{Btu} / \mathrm{h}$ and with a balance point temperature $\left(\mathrm{T}_{\mathrm{C}}\right.$ ) of $36^{\circ} \mathrm{F}$. (See section 2.2 .1 for discussion of $\mathrm{T}_{C}$ )

Annual efficiency for step-modulating units depends upon several factors including:

- percentage of the heating season operating time in each of the two modes,

- average outdoor temperature for each mode,

- average steady-state efficiency over the various firing rates in the non-cycling mode,

- infiltration loss in the non-cycling mode, and

- part-load efficiency in the cycling mode. 
The first two factors can be developed by considering heater sizing and through analysis of representative weather data. The remaining factors are determined via additional test measurements and calculations. Each of the factors is described in detail in the sections that follow.

\subsubsection{Percent of Operating Time in Each Mode}

Two assumptions provide a basis for defining the percent of operating time spent in each of the two modes: (1) at an outdoor temperature of $65^{\circ} \mathrm{F}$, heating requirements no longer exist, and (2) at the outdoor design temperature for vented room heaters of $15^{\circ} \mathrm{F}$ (see appendix A for development of this value) the heater output rate needed to meet the heating requirement is equal to the maximum heater output rate divided by $(1+\alpha)$ where $\alpha$ is the heater oversize fraction. Here output rate is defined as the product of input rate and steady-state efficiency. A relationship between heater output and outdoor temperature can then be expressed:

where

$$
\frac{Q_{\text {out,max }} /(1+\alpha)}{Q_{\text {out }, \min }}=\frac{65-15}{65-T_{c}}
$$

Qout,max is rated maximum output rate,

Qout,min is rated minimum output rate.

$\mathrm{T}_{C}$ is the outdoor temperature where the modulating mode begins (see figure 4 ). This implies that heating load is a linear function of outdoor temperature. In these test procedures $\alpha$ is assigned a value of zero. Under this assignment, at outdoor design temperature of $15^{\circ} \mathrm{F}$ the heater operates at maximum firing rate.

A plot of $T_{C}$ versus the ratio of minimum to maximum output is shown in figure 5 for fixed values of $\alpha$. The cycling mode (as shown in figure 4) is between outdoor temperature $\mathrm{T}_{\mathrm{C}}$ and $65^{\circ} \mathrm{F}$. The modulating mode is between $\mathrm{T}_{\mathrm{C}}$ and the minimum outdoor temperature, which for household heaters is typically $15^{\circ} \mathrm{F}$. Through analysis of typical weather data, the time in each mode can then be defined as a fraction of total heating season degree hours. The analysis involves a bin method calculation of hours in various temperature ranges. The steps in the calculation are presented in the column headings of table 1. See column (14) and columns (1) through (5) of table 1. A graphical example is also shown in figure 6 .

\subsubsection{Average Outdoor Temperature in Each Mode}

The average outdoor temperature in the cycling and non-cycling modes $\mathrm{T}_{\mathrm{oa}}$ and $\mathrm{T}_{\mathrm{oa}}$ ', respectively (as shown in figures 7 and 8 ) are developed from representative national average weather data. Tabulated data and temperature calculations for one city having a 4200 degree day heating season are shown in table 1. The average of calculated values for eight cities and the basis for figures 7 and 8 are presented in table two. The eight cities are listed in appendix, table A2. These eight cities all fall within a range of +5 percent of the national average (heater population weighted) of 4400 degree dayss. 
Referring to table 1 , calculation of $\mathrm{T}_{\mathrm{oa}}$ and $\mathrm{T}_{\mathrm{oa}}$ ' is as follows: for each temperature range, the mean temperature (col. 2) and number of hours spent in the range (col. 3) are determined from a compilation of historial weather data [5]. From this the number of degree hours in each range (col. 5) is obtained. $\mathrm{T}_{\mathrm{O}}$ a represents the average outdoor temperature between $65^{\circ} \mathrm{F}$ and $\mathrm{T}_{\mathrm{C}}$. To obtain $\mathrm{T}_{\mathrm{oa}}$, col. 5 and col. 3 are therefore summed cumulatively (upward in table 1) frorn $62^{\circ} \mathrm{F}$ to $\mathrm{T}_{\mathrm{C}}$ yielding col. 6 and col. 7 , respectively. For each $\mathrm{T}_{\mathrm{C}}$ given in col. 2 , col. 6 divided by col. 7 represents the corresponding number of degrees below $65^{\circ} \mathrm{F}$. This number is given in col. 8. $\mathrm{T}_{\mathrm{oa}}(\mathrm{col} .9)$ is $65^{\circ} \mathrm{F}$ minus col. 8. The same approach is taken in calculating $\mathrm{T}_{\mathrm{o}}$ ' except that the cumulative summation is from $15^{\circ} \mathrm{F}$ to $\mathrm{T}_{c}$ rather than from $65^{\circ} \mathrm{F}$ to $\mathrm{T}_{C}$. The result of these calculations is a value of $\mathrm{T}_{\mathrm{oa}}$ and $\mathrm{T}_{\mathrm{oa}}$ ' for each $\mathrm{T}_{\mathrm{C}}$. A plot of these parameters for the values in table 2 is shown in figure 7 . For any given heater, equation (1) can be used to determine $\mathrm{T}_{\mathrm{C}}$, for which values of $\mathrm{T}_{\mathrm{oa}}$ and Toa' can be obtained from figure 7. Alternatively, equation (1) and the results of the previous temperature calculations can be combined to eliminate the intermediate calculations of $\mathrm{T}_{\mathrm{c}} \cdot \mathrm{T}_{\mathrm{oa}}$ and $\mathrm{T}_{\mathrm{O}}$ ' can be obtained from figure 8 where percent of time in cycling modes, $\mathrm{T}_{\mathrm{oa}}$ and $\mathrm{T}_{\mathrm{oa}}$ ' (columns 5, 6a, and $6 \mathrm{~b}$ of table 2, respectively) are plotted vs the min/max heater output ratio (col. 7 of table 2).

\subsubsection{Average Steady-State Efficiency}

Due to an increase in excess air at below maximum firing rates, there is usually a drop in steady-state efficiency in the non-cycling mode as fuel input rate is reduced. An average steady-state efficiency is, therefore, needed to represent operation in this mode. The average steady-state efficiency is calculated by linear interpolation between the steady-state efficiency at the minimum rated input, which corresponds to temperature, $\mathrm{T}_{\mathrm{c}}$, and the steady-state efficiency at the maximum rated input for the heater, which corresponds to a temperature of $15^{\circ} \mathrm{F}$. These efficiencies are determined in accordance with the DoE test procedure using $\alpha=0 . *$ The average efficiency $\left(n_{\mathrm{ss}}\right)$ will correspond to the efficiency when firing at temperture $\mathrm{T}_{\mathrm{oa}}$ ' and is given by

$$
n_{s s}=\left[n_{s s, \max }-n_{s s, \min }\right] \frac{\mathrm{T}_{\mathrm{c}}-\mathrm{T}_{\mathrm{oa}}}{\mathrm{T}_{\mathrm{c}}-15}+n_{\mathrm{ss}, \text { min }}
$$

In general, the arithmetic mean of the steady-state efficiencies may be used in place of equation (2) with a resulting error of about one percentage point.

* The DoE test procedure [3] lists a value of $\alpha=0.7$ which was applicable to central furnaces, and was originally adopted for use with vented heaters. Since the typical oversize factor is unknown for vented heaters the use of $\alpha=0.7$ would be arbitrary. In order to reduce the complexity of the calculation procedures for modulating type heaters, a value of $\alpha=0$ is applied for all calculated efficiencies reported here. 


\subsubsection{Infiltration Loss in the Modulating Mode}

On-period infiltration loss $\left(L_{I, O N}\right.$ ) is an energy efficiency debit for heaters using indoor air for combustion and draft hood dilution. The loss of efficiency due to infiltration of outdoor air at $\mathrm{T}_{\mathrm{oa}}$ ' (which is subsequently heated to an indoor temperature of typically $70^{\circ} \mathrm{F}$ ) is subtracted from the weighted average steady-state efficiency calculated by the above procedure. Average onperiod infiltration loss is calculated in the same manner as steady-state efficiency. On-period infiltration losses are obtained via the current DoE test procedure [3] and the average infiltration is taken to be the arithmetic mean of the values determined at the maximum and minimum input rates. 


\subsection{CURRENT TEST PROCEDURE}

The current test procedure for determining the annual efficiency of vented heaters [ 3] applies only to units equipped with single-stage controls. While not directly applicable to modulating-type units, only minor modifications to the procedure are necessary to accommodate these types of controls. A cursory review of the procedure will, therefore, be provided here. A more detailed description of the procedure is provided in references [3, 4].

The existing procedure involves conducting a steady-state performance test on the heater, plus measuring flue gas temperatures at specific times during the heat-up and cool-down from steady-state conditions. Specific measurements at steady-state include flue and stack gas temperature and $\mathrm{CO}_{2}$ concentration. Two temperature measurements during heat-up and three during cool-down provide the basis for exponential approximations for the temperature-time profiles.

In addition to the above experimental data, a knowledge of several factors describing mass flow rates through the flue and stack during on- and off-periods is required. Values for these factors may be either measured or assigned according to the type of unit under test.

Based upon the experimental data and assigned system factors, thermal losses associated with heater operation are determined. These losses expressed as a percentage of the fuel input rate are:

$\mathrm{L}_{\mathrm{L}} \quad=$ Latent Heat Loss due to the presence of uncondensed water vapor in the flue gas.

$\mathrm{L}_{\mathrm{S}, \mathrm{ON}}=$ On-cycle Sensible Heat Loss due to the venting of combustion products and excess air at a temperature above room temperature.

$\mathrm{L}_{\mathrm{L}, \mathrm{ON}}=$ On-cycle Infiltration Loss due to heating the on-period combustion and draft control air from outdoor temperature ( $\mathrm{T}_{\mathrm{OA}}$ ) to room temperature.

$\mathrm{L}_{\mathrm{S}, \mathrm{OFF}}=$ Off-period Sensible Heat Loss due to heating the off-period room air discharged at a temperature in excess of the room temperature.

$\mathrm{L}_{\mathrm{I}, \mathrm{OFF}}=$ Off-period Infiltration Heat Loss due to heating the off-period room air loss from outdoor temperature to room temperature.

Steady-state efficiency is given in terms of latent heat 1 oss, $\mathrm{L}_{\mathrm{L}}$, and on-period sensible heat loss at steady-state, $\mathrm{L}_{\mathrm{S}, \mathrm{ON}, \mathrm{sS}}$. Part-load efficiency, $\eta_{\mathrm{u}}$, is expressed as a function of the five losses:

$$
\eta_{\mathrm{u}}=100-\mathrm{L}_{\mathrm{L}}-\frac{\mathrm{t}_{\text {on }}}{\mathrm{t}_{\text {on }}+\mathrm{PF} \times \mathrm{t}_{\text {off }}} \quad\left(\mathrm{L}_{\mathrm{S}, \mathrm{ON}}+\mathrm{L}_{\mathrm{S}, \mathrm{OFF}}+\mathrm{L}_{\mathrm{I}, \mathrm{ON}}+\mathrm{L}_{\mathrm{I}, \mathrm{OFF}}\right)
$$




$$
\begin{aligned}
& t_{\mathrm{on}}=\text { typical on-period time - minutes, } \\
& \mathrm{t}_{\mathrm{off}}=\text { typical off-period time - minutes, } \\
& \mathrm{PF} \quad=\text { Pilot fraction (as fraction of total fuel input rate). }
\end{aligned}
$$

The part-load efficiency is then combined with the steady-state efficiency $\left(n_{\mathrm{ss}}\right)$ and pilot fraction to yield the annual fuel utilization efficiency.

$$
\text { EFFYA }=\frac{n_{\text {ss }} \times n_{u} \times 4400}{n_{\text {SS }} \times 4400+2.5 \times n_{u} \times \text { PF } \times 4600}
$$

where the additional parameters are:

$$
\begin{aligned}
4400= & \text { average annual degree days for vented heaters (see appendix A) } \\
4600= & \text { average non-heating season hours per year that all the energy } \\
& \text { to the pilot is assumed wasted. }
\end{aligned}
$$

\subsection{MEASUREMENTS AND CALCULATIONS FOR HEATERS WITH STEP-MODULATING CONTROLS}

For single-stage heaters there is only one fuel input rate at which measurements can be made (the maximum input rate). Modulating-type heaters, however, operate both at reduced firing rate during the cycling mode and anywhere between the reduced and maximum rates during the non-cycling mode. Accordingly, test measurements must be made at the maximum input rate as well as the reduced setting. Since the heater with step-modulating control cycles on-off only at the reduced input rate, all part-load cycling losses must be determined at the reduced input. In addition, to account for operation in the non-cycling mode, as described in sections 2.2 .3 and $2.2 .4, L_{S}, O N$ and $L_{I}$, ON must be determined at naximum fire as well. It is not necessary to know either of the off-cycle losses at high fire ( $\mathrm{L}_{\mathrm{S}, \mathrm{OFF}}$ and $\mathrm{L}_{\mathrm{I}, \mathrm{OFF}}$ ) because no off period loss occurs at that input rate with the step-modulating-type control.

The recommended procedure for calculating the annual fuel utilization efficiency for modulating type heaters essentially involves determination of losses and efficiencies for each of the operating modes -- cycling and noncycling and weighting of these parameters according to the fraction of time spent in each mode.

The procedure for calculating annual efficiency for the step-modulating heaters is summarized below in nine steps. The detalled procedure consisting of 20 steps is included in appendix B, along with a sample calculation. A computer program (FBVH) for conducting the complete calculation applicable to furnaces, boilers, and vented heaters is included in appendix $C$.

(a) Determine minimum and maximum heater outputs from the minimum and maximum input rates and measured steady-state efficiency at these two input rates. (For details see steps $1-7$ of appendix B.) 
(b) Using minimum/maximum heater output from step (a), determine the percent of heating season in each mode. Find the percent of time in cycling mode from figure 8. Percent of non-cycling mode is 100 percent less the percentage of cycling mode.

(c) Determine the average outdoor temperature in the cycling mode, $\mathrm{T}_{\mathrm{oa}}$, and in the non-cycling mode, $\mathrm{T}_{\mathrm{oa}}$ ', from figure 8 at the point corresponding to the min/max output determined from (a).

(d) Determine part-load efficiency in the cycling mode using the value of $\mathrm{T}_{\mathrm{Oa}}$ and the prescribed DoE test procedure [3].

(e) Determine the average steady-state efficiency in the non-cycling mode. Use the average of steady-state efficiency measured at the maximum and minimum input rates from step (a).

(f) Determine part-load efficiency in the non-cycling mode by subtracting infiltration loss, LI, ON, from the average steady-state efficiency in step (e). Use $\mathrm{T}_{\mathrm{oa}}$ ', to calculate infiltration loss in the non-cycling mode.

(g) Determine weighted average steady-state efficiency using steady-state efficiencies at the minimum input rate from step (a) and the average determined for the non-cycling mode from step (e). Weight each by the percent of heating season in each mode (determined from step (b)).

(h) Determine average part-load efficiency for the heating season using the corresponding part-load efficiencies for the cycling and non-cycling modes and the percent of heating season in each mode.

(i) Determine annual efficiency using average part-load efficiency and average steady-state efficiency.

\subsection{CALCULATIONS FOR HEATERS WITH TWO-STAGE CONTROLS}

This type of control cycles the burner at low fire for outside air temperatures between $65^{\circ} \mathrm{F}$ and $T_{c}$ and at higher fire for temperatures $T_{c}$ and below (see figure 1). Evaluation of the annual fuel efficiency of heaters with two-stage controls involves the same test measurements required for step-modulating type units, and only slightly different calculations. The calculations are described in detail in appendix $B$. 


\subsection{PRESENT DESIGN}

Figure 3 shows that modulating controls will indeed affect annual efficiency as evidenced by the variation in part load efficiency with heating load. As shown, efficiency improves as the heating load is increased. This is due both to a reduction in heater cycling (see Modulating Mode of figure 4) and therefore, off-cycle losses, and also in the higher steady-state efficiency at the higher full input rates. The maximum efficiency of currently designed heaters is realized in the non-cycling mode.

\subsection{HEATERS EQUIPPED WITH THERMAL DAMPERS}

Measured on-period and off-period stack losses of a room heater with and without a thermal stack damper installed were measured. Detailed test results and data are in tables 3 \& 4. Data for damper $A$ is presented graphically in figure 9. See [6] for additional information including description of tracer gas test method use to measure the off period losses. The shaded area represents energy savings due to the damper. Figure 9 shows for that heater, as fuel input rate is reduced from maximum to lower input rates, energy savings due to the damper continuously increase. The significance of these findings is that a test conducted per the DoE test procedure [3] only at the maximum input rate does not reflect the potential energy savings of the thermal type stack damper when it is installed on a heater having a step-modulating or two-stage thermostat control.

A summary of energy savings calculated using the calculation procedure of appendix $\mathrm{C}$ for three heaters with three different models of thermal dampers is shown in table 5. Results presented in table 5 show that energy savings is dependent on type of heater and stack damper as well as type of thermostat used, and the reduced fuel input rate of the step-modulating type thermostat.

\subsection{HEATERS WITH REDUCED COMBUSTION AIR AT REDUCED HEAT INPUT RATES}

Although heaters tested have shown a reduced part-load efficiency at reduced input rates, it is possible that heaters can be designed to use less excess air at the reduced input rate, thereby, actually increasing part-1oad cycling mode efficiency at the lower rate to above the non-cycling mode operating efficiency. This is possible because at reduced input rates the ratio of heat transfer surface area to combustion products mass flow rate is greater. Test procedures outlined here will allow credit for any such innovative designs that result in reduced excess combustion air at reduced fuel input rate.

The potential for energy savings with reduced excess air has been demonstrated in the laboratory by intentionally reducing the excess air at reduced input rate. The excess combustion air values at a minimum input are presented in table 6 for a heater in "as received" condition and after reducing excess combustion air. Excess air was reduced in these test by using a flue baffle placed in the exit of the heat exchanger. Baffling of the heat exchanger was limited 
in order not to increase carbon monoxide in the flue gases above the amounts found prior to any restriction of the flue. Data obtained at the maximum firing rate and at the minimum input rate with restricted excess combustion air is shown in table 6.

The effect of reduced excess air on efficiency can be quite significant. As shown in table 6 , energy savings of from 6 to 22 percent were calculated. 


\section{CONCLUSIONS}

A procedure for evaluating the annual operating efficiency of vented heating equipment with a step-modulating thermostat or two-stage control has been developed. This procedure is essentially the same as the existing DoE test procedure for vented heaters, but calls for tests and calculations to be performed at maximum as well as minumum firing rates. Analyses of weather data for typical cities, and assumptions concerning heater sizing, provide a means of combining the cycling and non-cycling efficiencies to yield a "weighted" annual fuel efficiency.

This rated annual efficiency is considered to be reflective of the differences inherent with cycling and non-cycling modes of operation which apply with modulating-type controls. Since procedures developed here are an extension of current DoE test procedures, these procedures are believed to be useful for comparing the annual efficiency of heaters with modulating type controls vs the conventional on-of thermostat control used with some types of vented heaters. The bin calculation procedures developed here are also expected to be applicable to certain furnaces equipped with the types of fuel modulating controls investigated in this study. Predicted annual energy with any of these procedures should be considered valid only for comparison purposes between equipment tested under laboratory conditions. These procedures as well as the current DoE test procedures should not be considered predictive of installed annual operating costs. Comprehensive treatment of the building and furnace interaction which are unique to each installation would be needed for that prediction and is beyond the scope of these procedures.

Comparison of heater efficiencies with single-stage and with step-modulating controls indicates that substantial improvements can be made. Maintaining the combustion air to fuel ratio with reduced input rate is a promising means of reducing energy consumption for heaters with step-modulating and two-stage controls. 
6. REFERENCES

[1] Kweller, E.R., and Mullis, W.F., "Proposed Amendments to Test Procedures for Vented Household Heaters," Letter Report prepared for Department of Energy, March 1980.

[2] Kweller, E.R., and Mullis, W.F., "Recommendations to DoE on Modifications of Test Procedures for Vented Gas and Oil Fueled Heaters," Letter Report, June 1979.

[3] Appendix 0 - Uniform Test Method for Measuring the Energy Consumption of Vented Home Heating Equipment, Federal Register, Vol. 43, No. 91, May 10, 1978.

[4] Kelly, G.E., et al., "Recommended Testing and Calculation Procedures for Determining the Seasonal Performance of Residential Central Furnaces and Boilers," NBSIR 78-1543, National Bureau of Standards, September 1978

[5] Engineering Weather Data, Department of the Air Force, AFM 88-29, the Army (TM 5-785) and the Navy (NAVFAC P-89), July 1978, Washington, DC 20330.

[6] Kweller, E.R., and Mullis, W.F., "Determination of Annual Efficiency of Vented Heaters Equipped with Thermally Activated Vent Dampers," ASHRAE Trans., Vo1. 87, Pt. 1, 1981. 


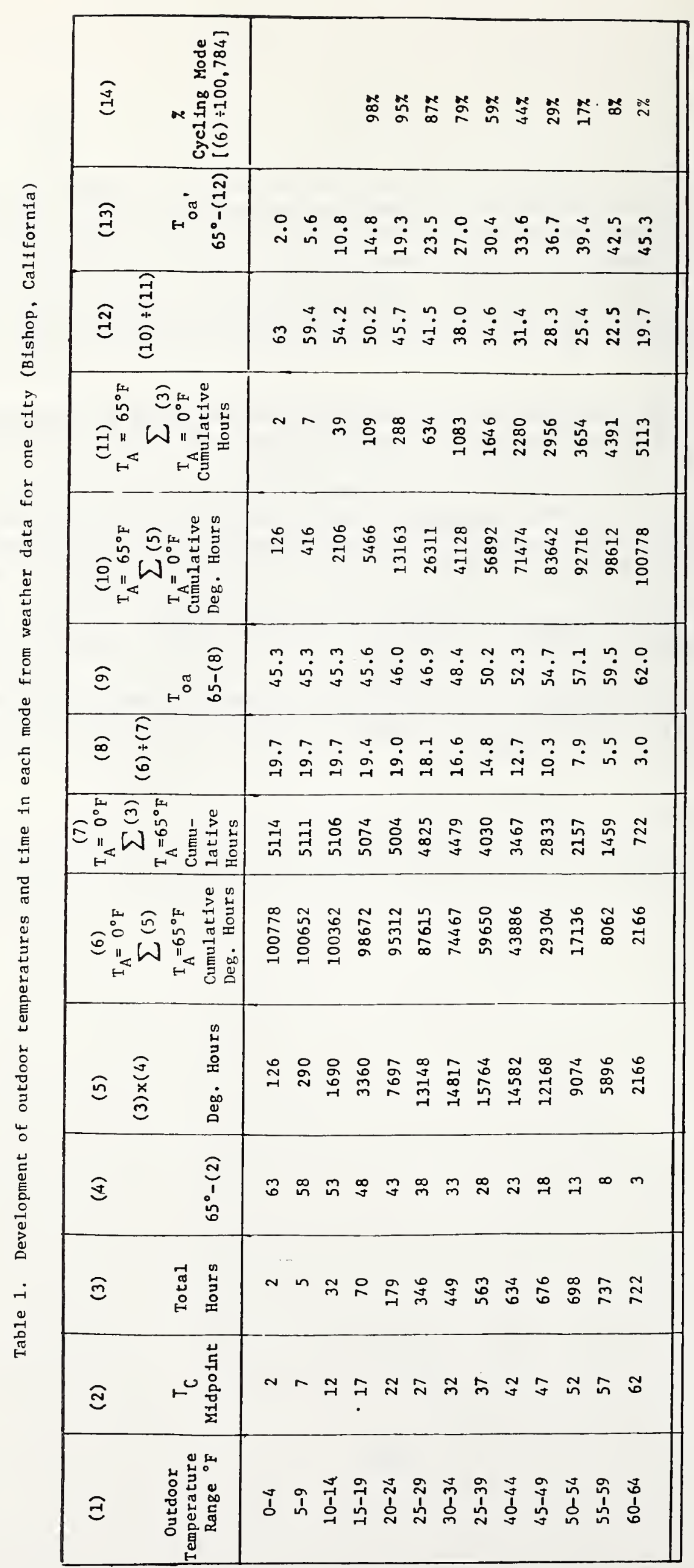




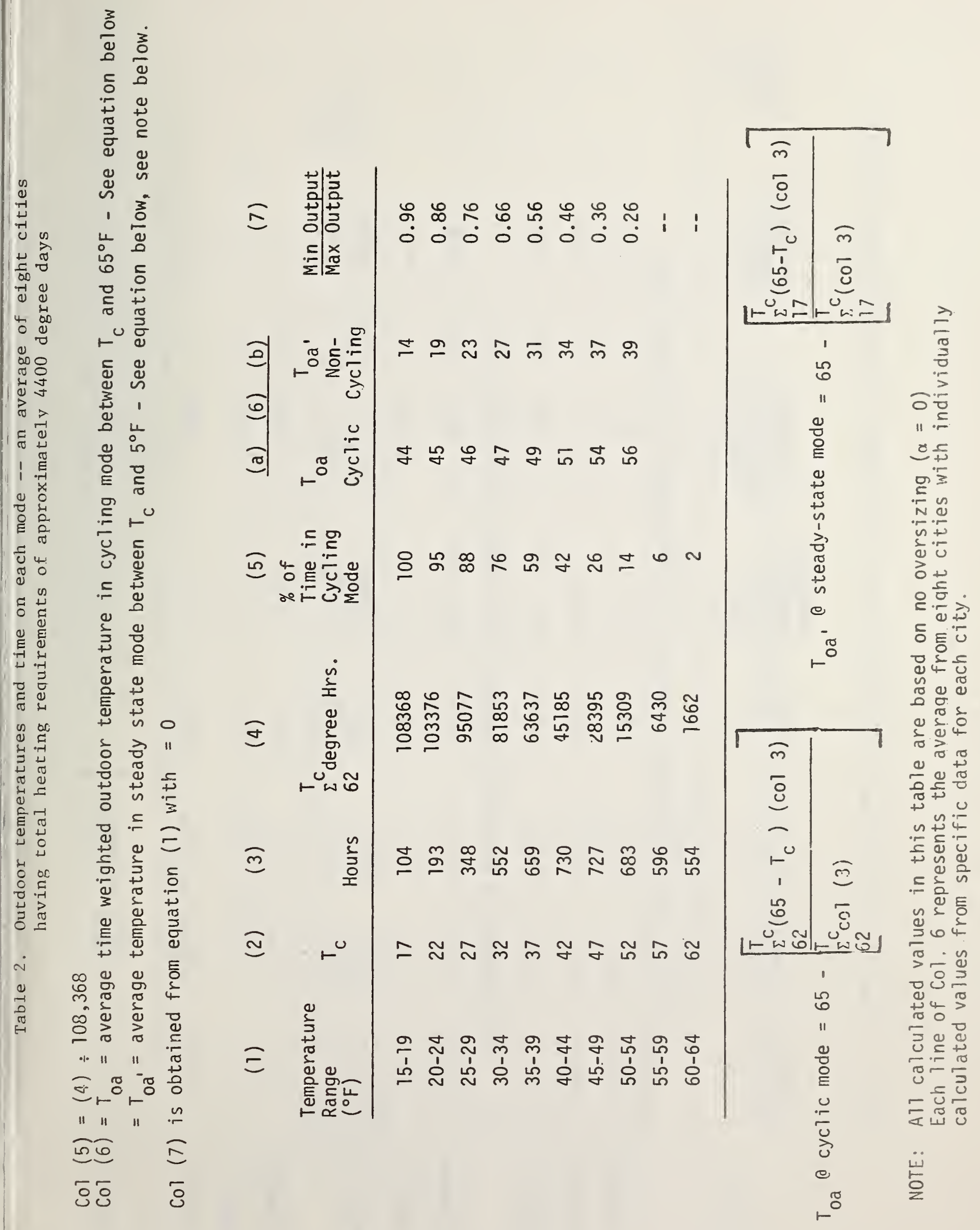




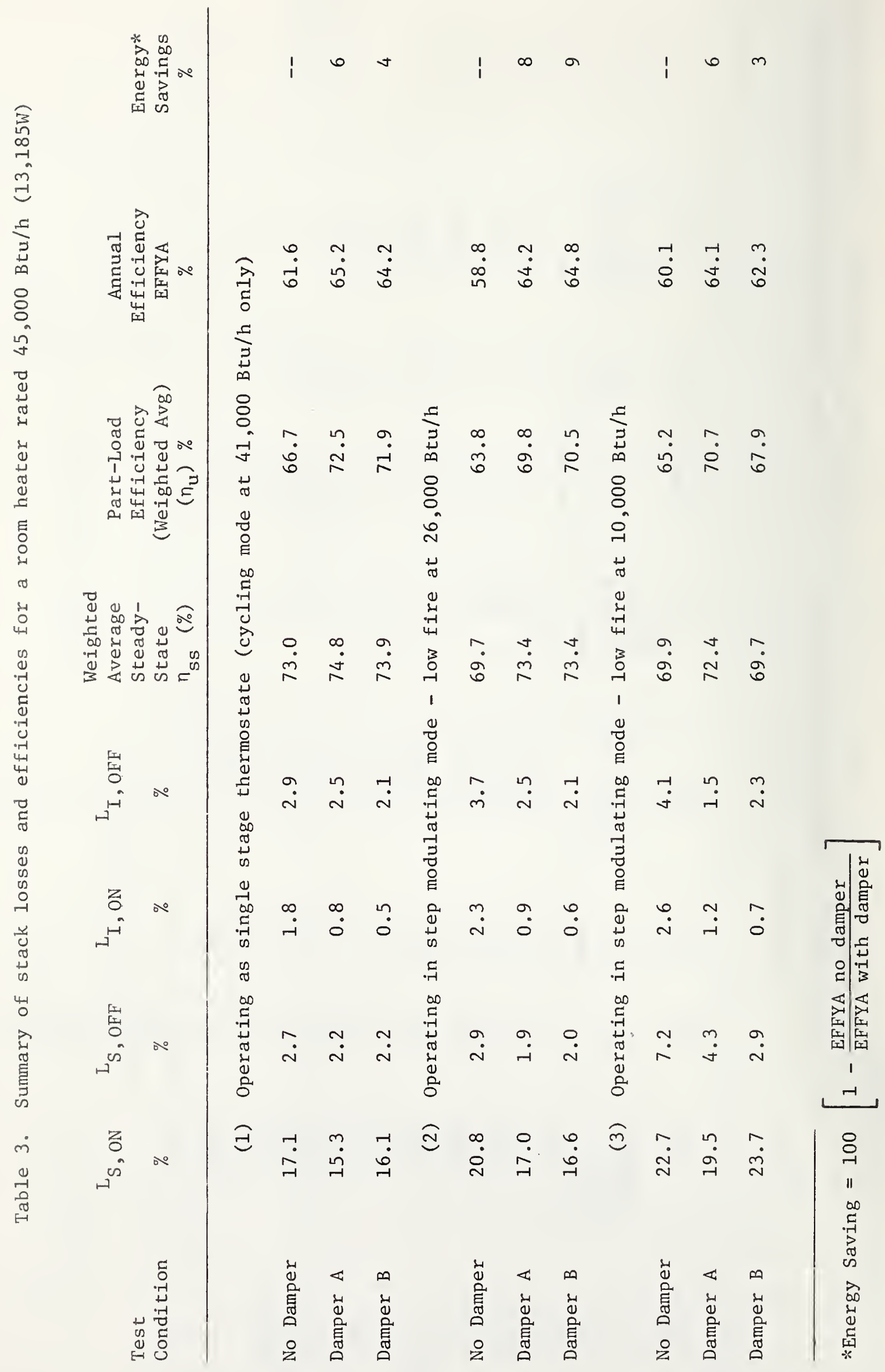




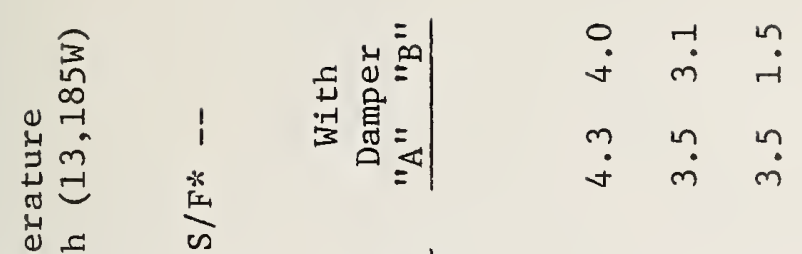

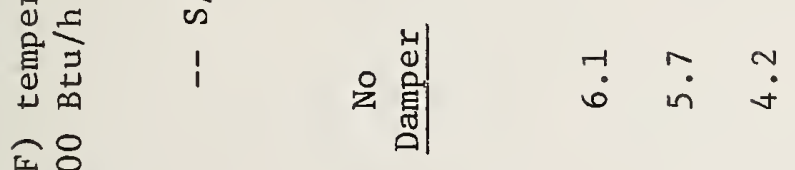

ㅍㅇㅇ

बin

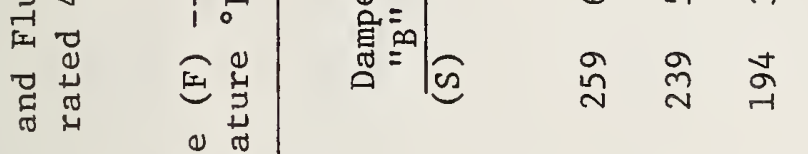

की

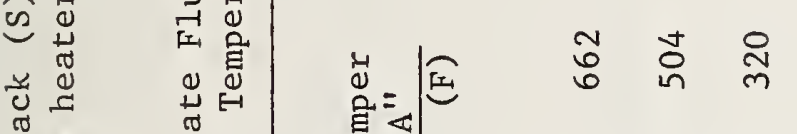

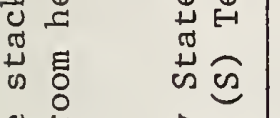

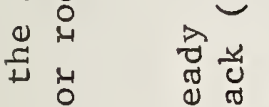

a

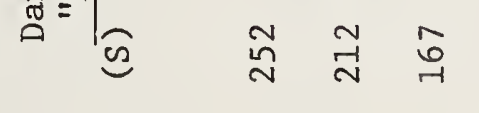

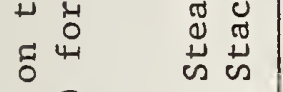

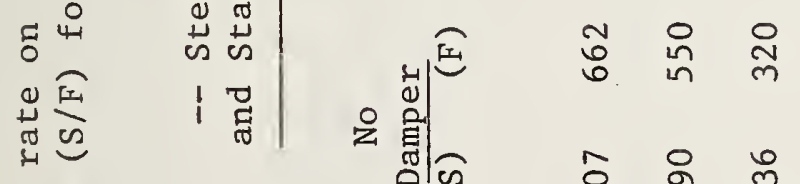

善営

ఏ

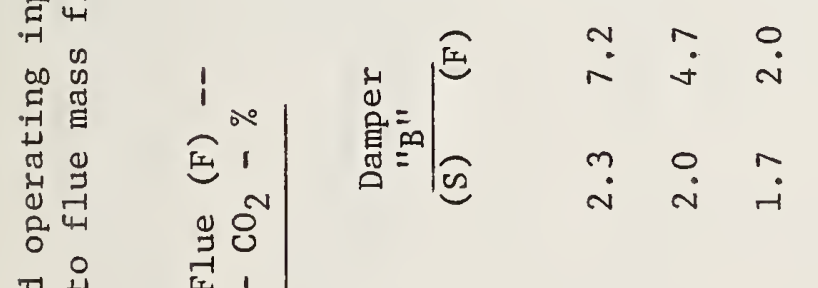

芑

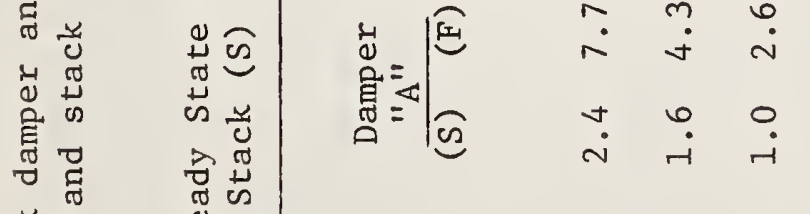

त

苟先

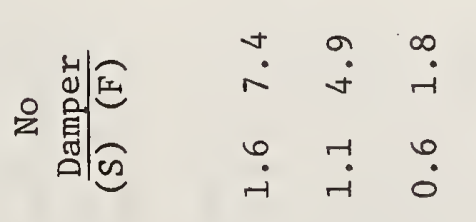

ปั

出 㟧

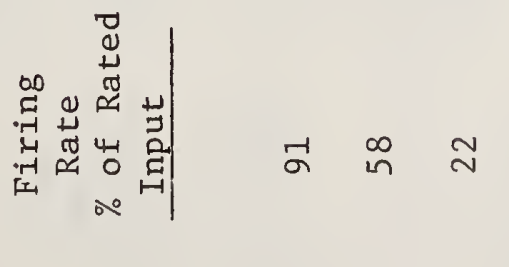

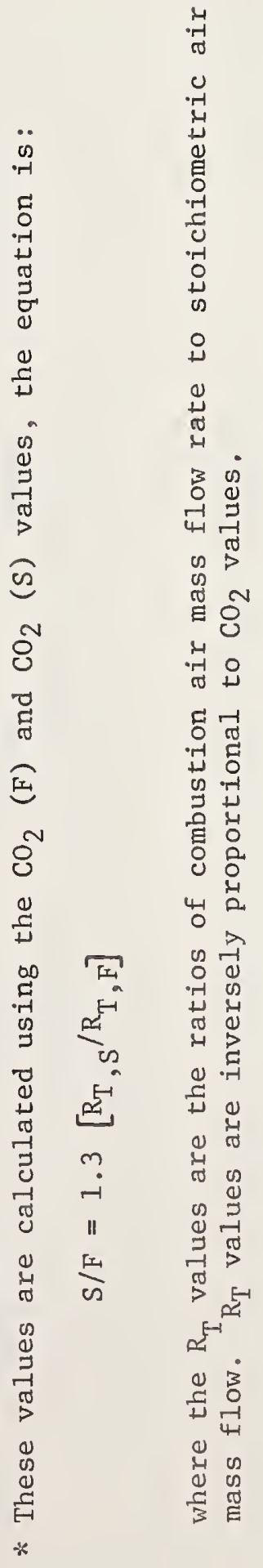




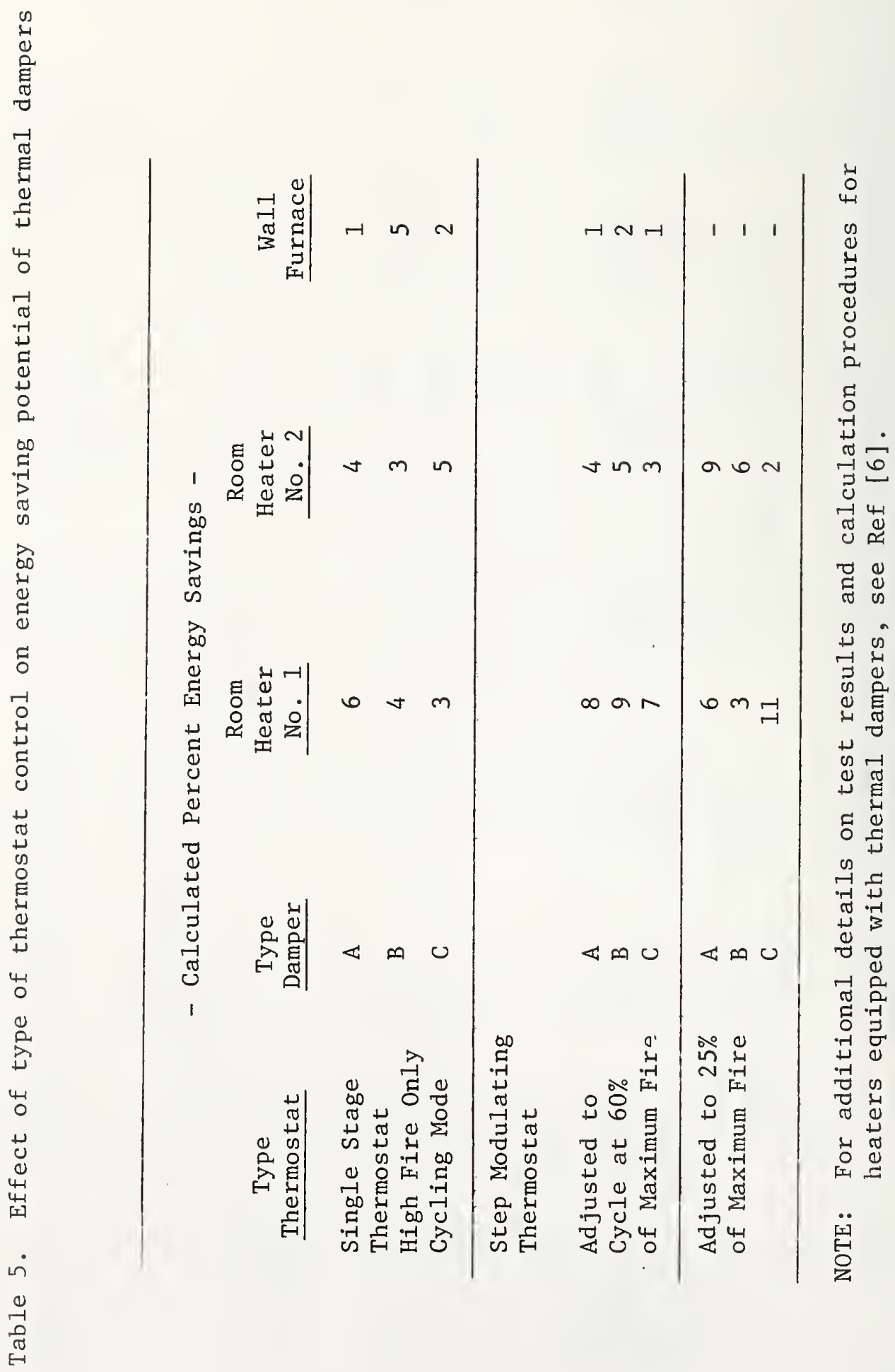




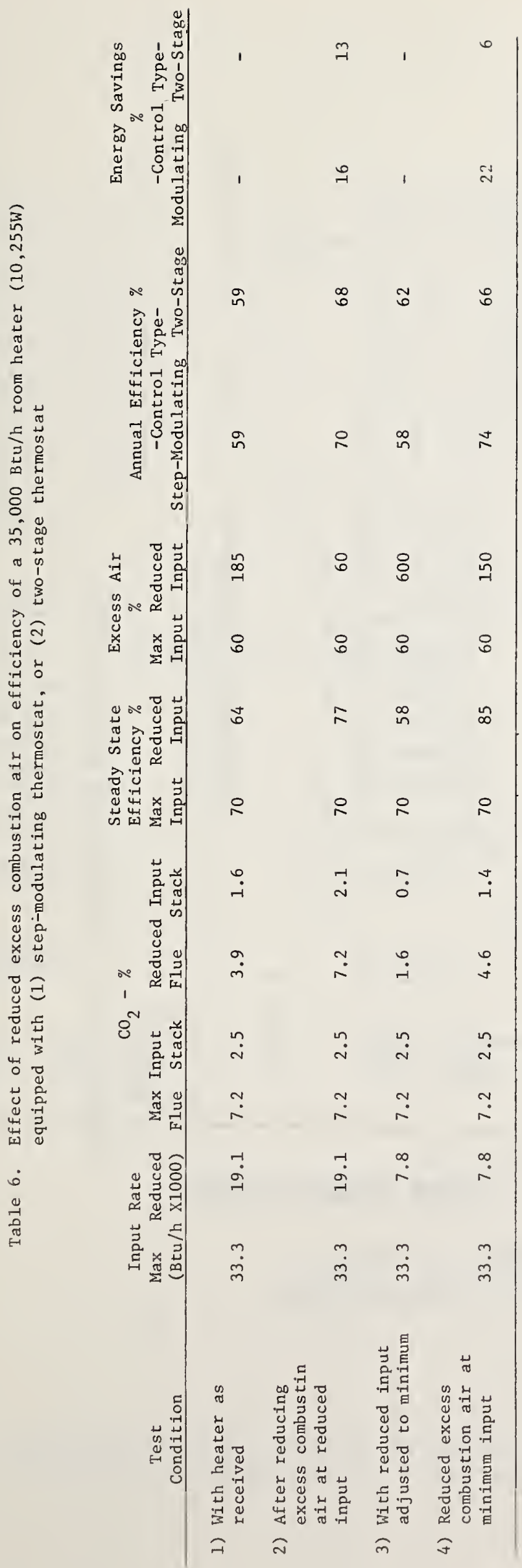




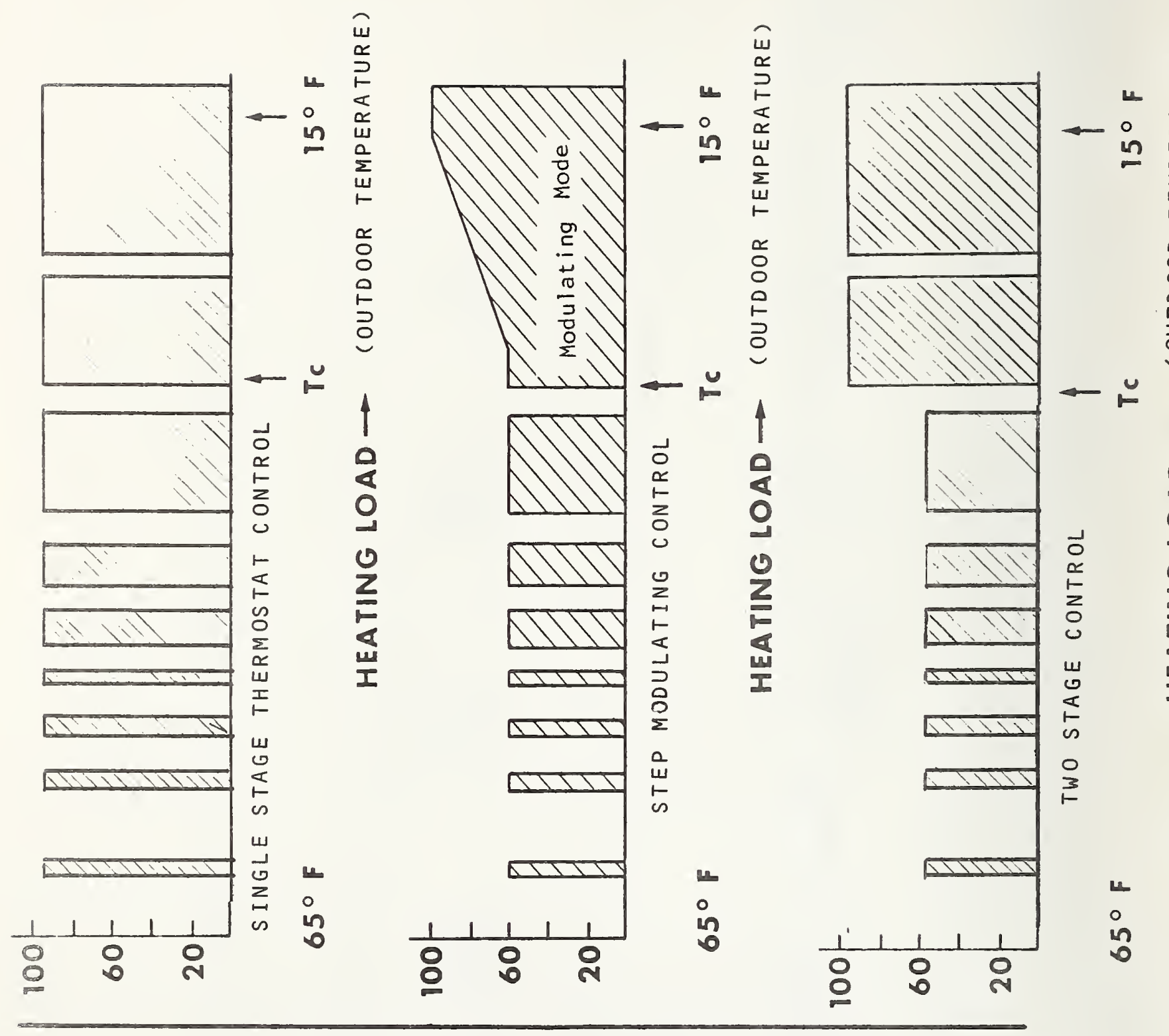

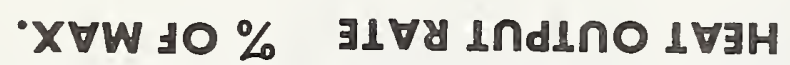




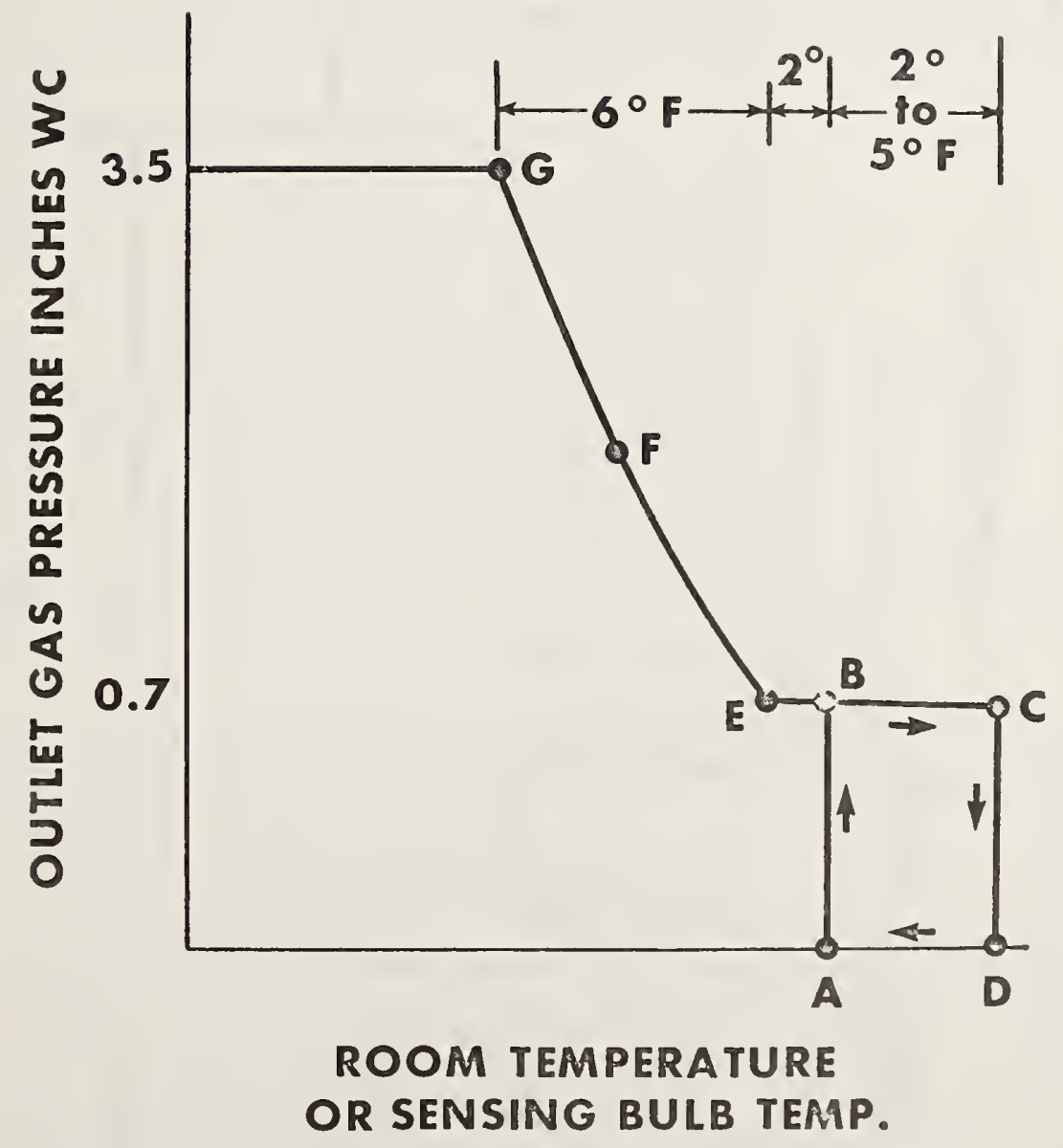

Figure 2. Outlet gas pressure from a step-modulating thermostat control in response to changing room temperature 


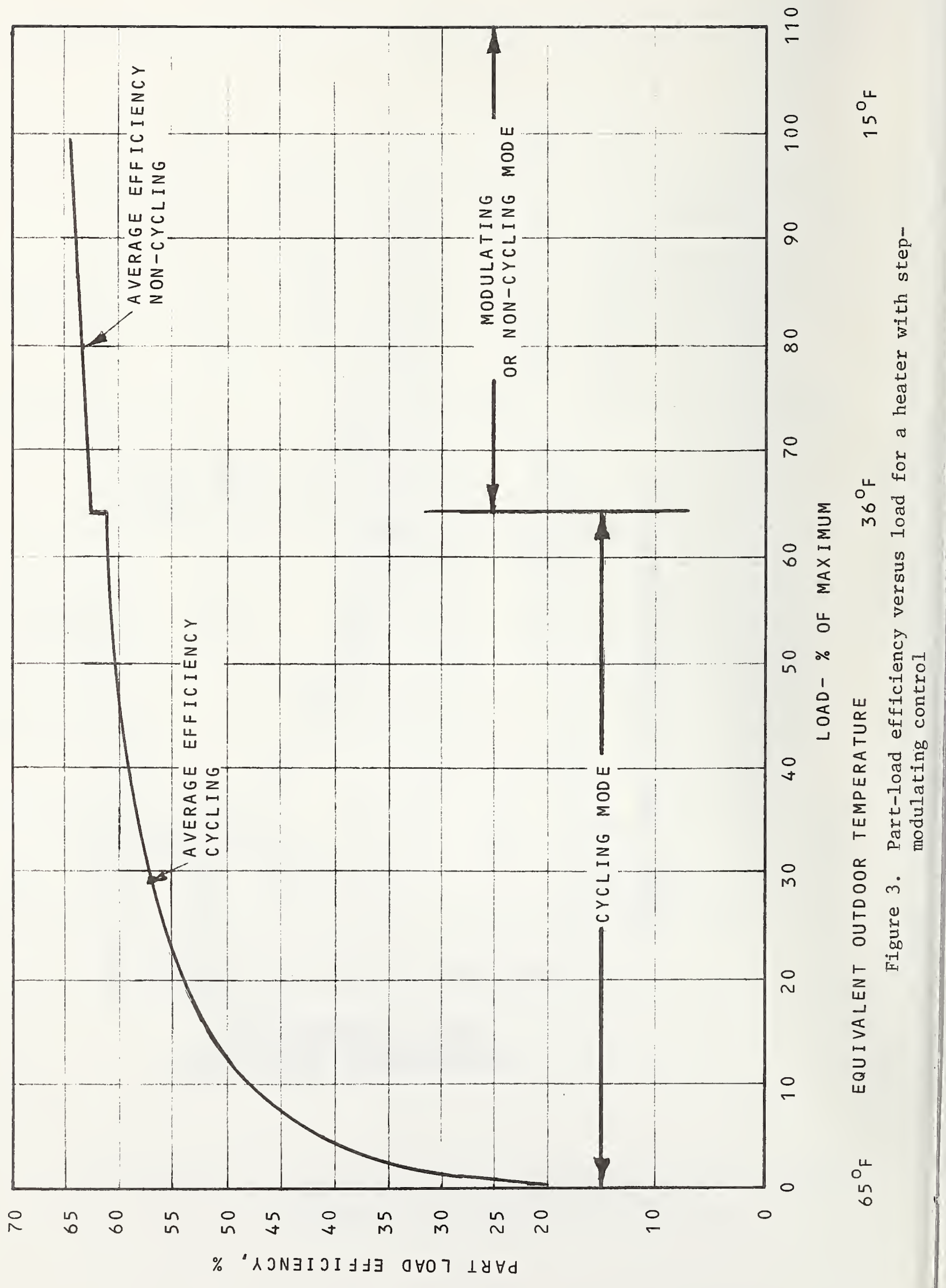



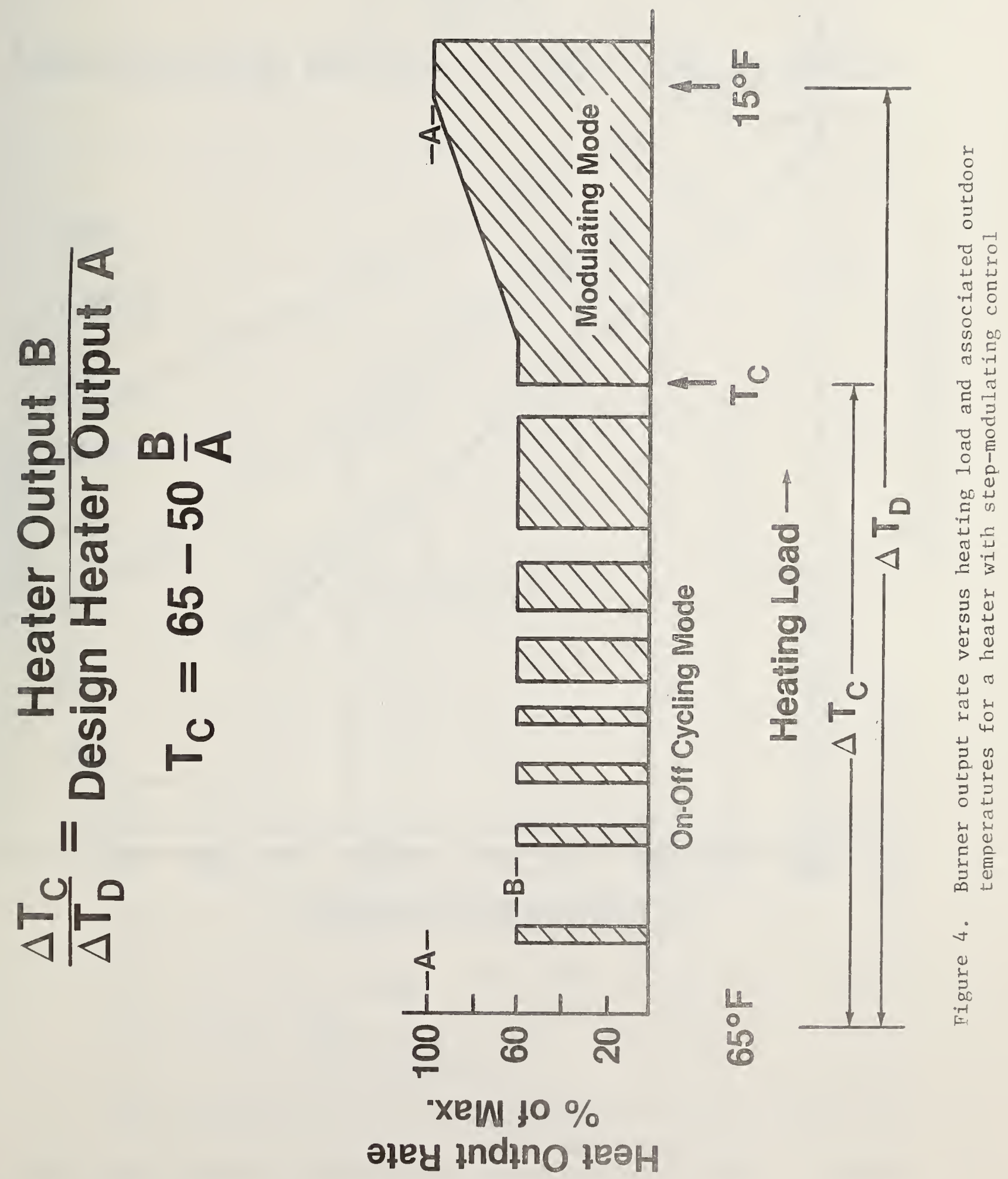


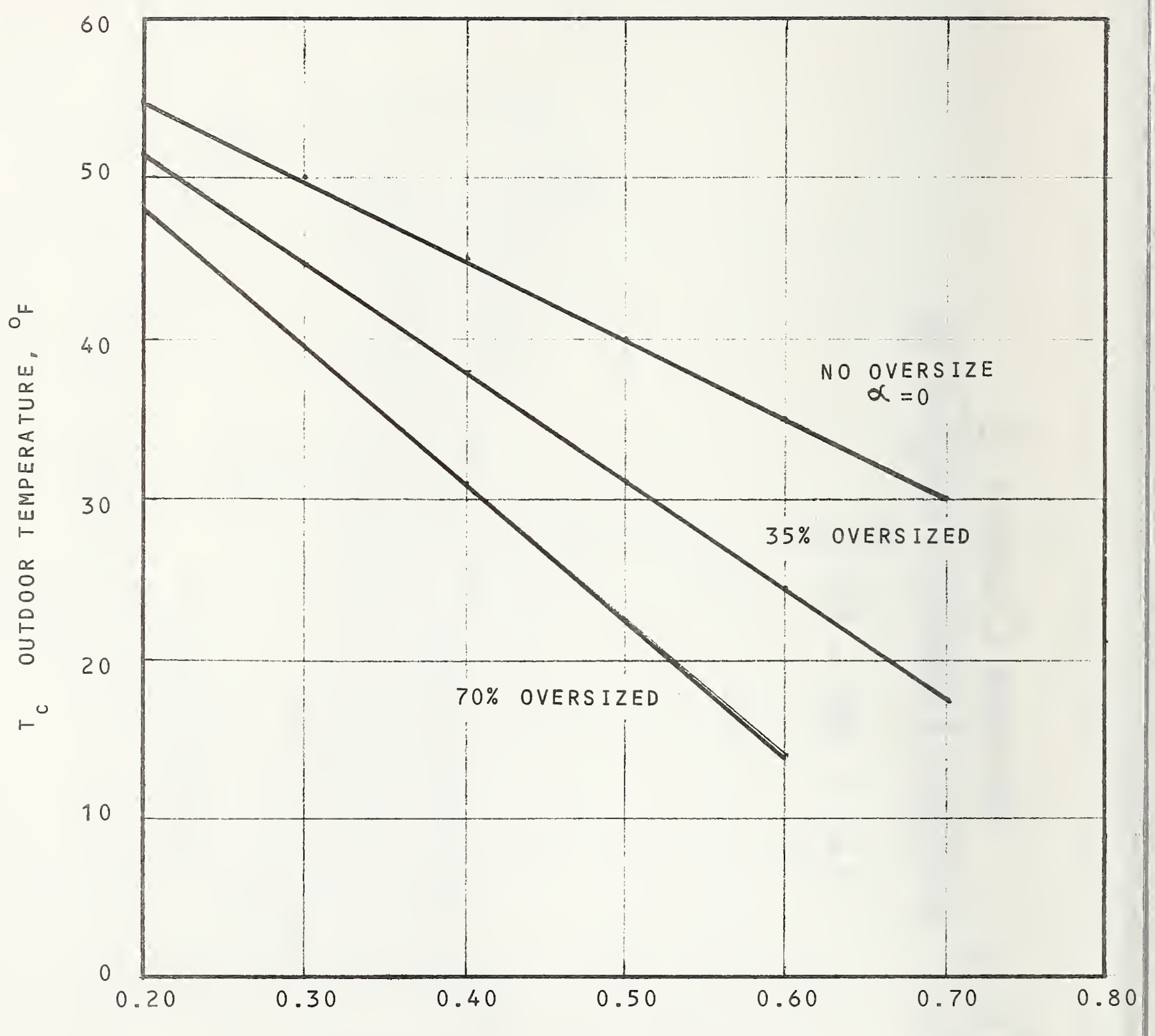

MINIMUM HEAT OUTPUT/MAXIMUM HEAT OUTPUT

Figure 5. Balance point temperature as a function of heater output ratio 


\section{Cycling Mode Fraction $=2530 \div 4400$ or $58 \%$}

Non-Cycling Mode $=100-58=42 \%$

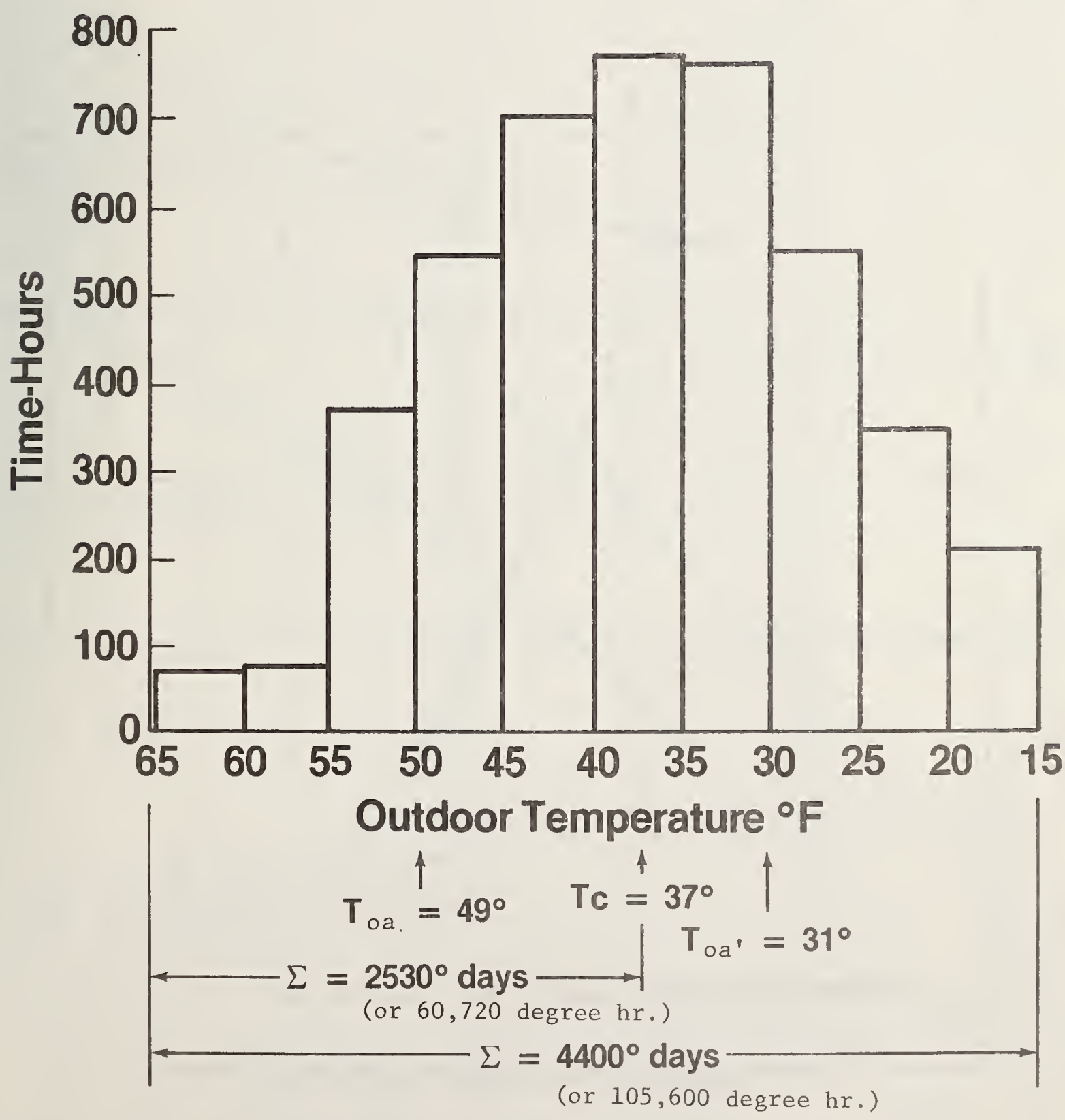

Figure 6. Example of bin method used to determine percentage of time in cycling mode 


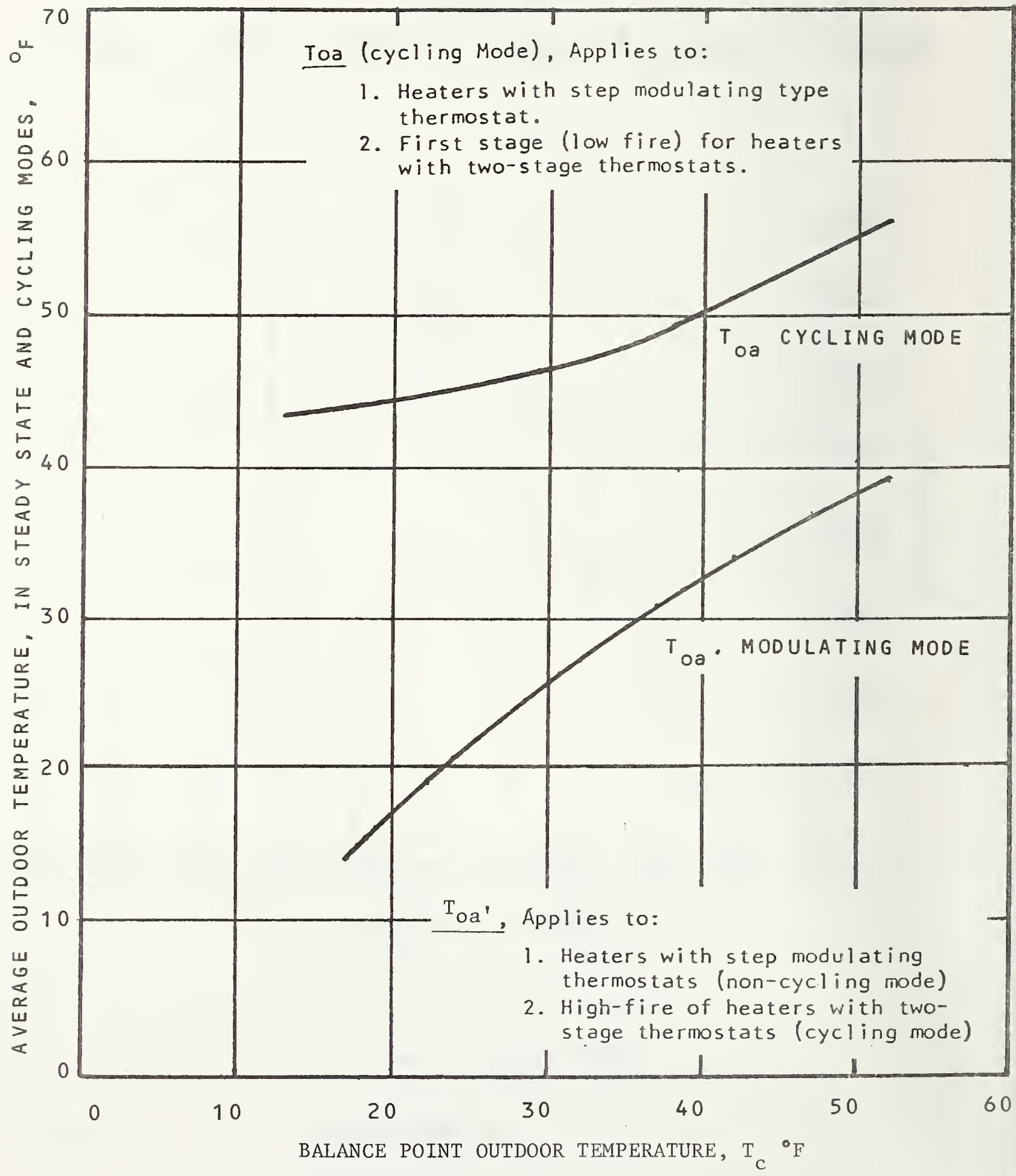

Figure 7. Average outdoor temperature in cycling and non-cycling modes versus balance point temperature $\left(\mathrm{T}_{\mathrm{c}}\right)$ 


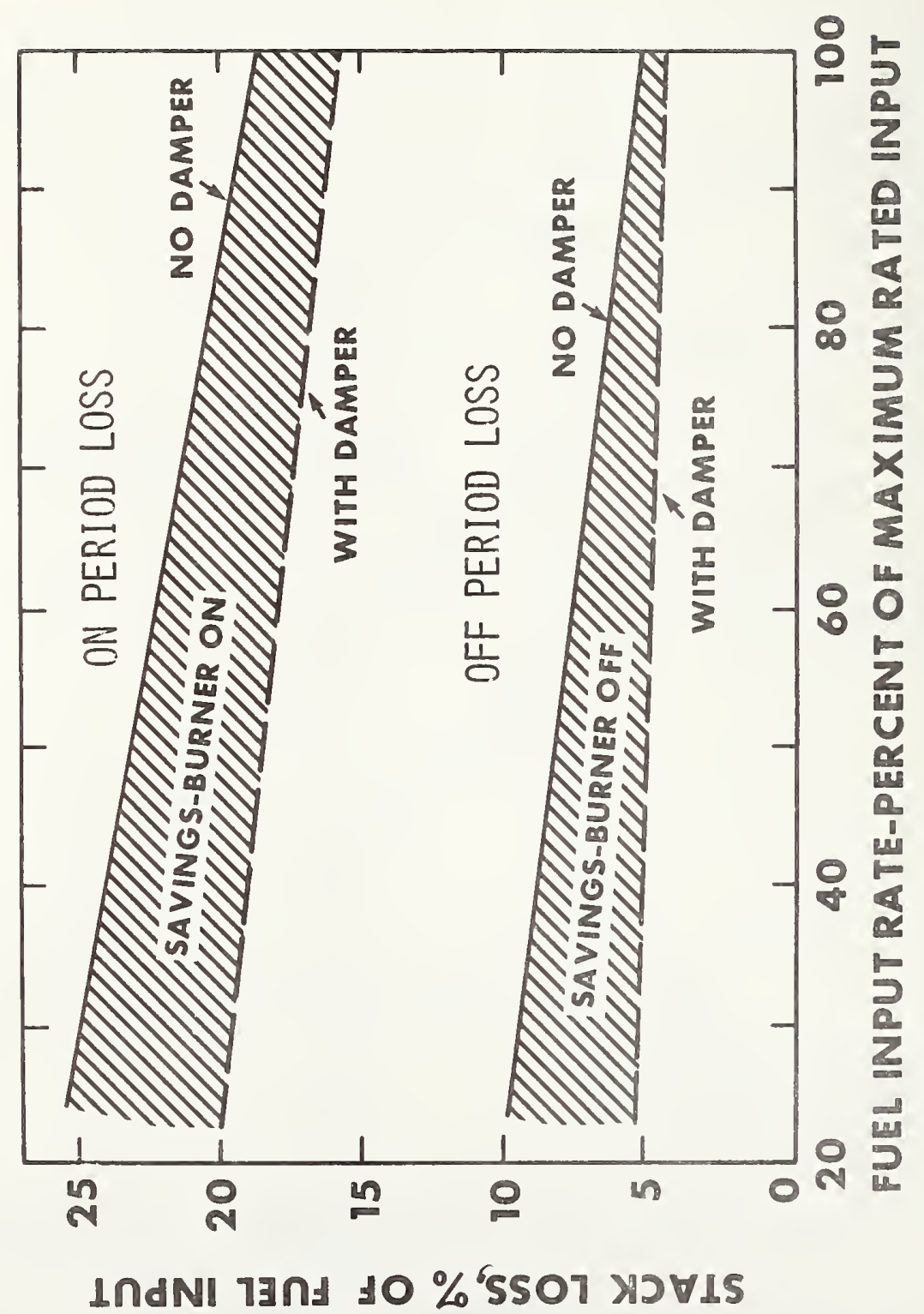

0
4
0

थ

ت

范

5

要

गั

它

동

43

牙

다

วิ

$4-13$

+

t)

(4)

4.

空

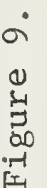


APPENDIX A

Determination of Outdoor Design Temperature and

Typical Annual Heating Degree Days

for Vented Household Heaters 
Determination of Average Heating Degree Days and Design Temperature for Vented Room Heaters

The $971 / 2$ winter design temperature is that dry-bulb temperature which will probably be exceeded $971 / 2$ percent of the time for winter months (December, January, February). Through consideration of the geographic distribution of vented room heaters throughout the U.S., combined with analyses of weather data, a single value or design temperature, representative of a "National Average" condition, can be obtained. This value will be different than the corresponding value of $5^{\circ} \mathrm{F}$ for furnaces used in [4], since the geographic distribution of furnaces and room heaters is not the same.

Based on 1970 census data, the total number of room heaters installed in each of the nine geographic regions of the United States is presented in table A1. Also presented in table Al are representative average number of heating season degree days for each of the nine regions. Based on these two pieces of information, a heater population weighted average of space heating degree days for room heaters can be obtained. Results of the average are presented at the bottom line of column (4) (4438 is rounded to 4400 degree-days, as the weighted national average). Although these data are based on the 1970 census now 11 years old, results are expected to be little affected if more recent census data were to be used since most vented heaters sold are replacement units for existing installations.

The outdoor design temperature can be approximated as the average of the design temperatures of a representative number of cities having heating seasons of about 4200 to 4600 degree-days. The heating degree-days and outdoor design temperatures for 13 cities falling in this range are presented in table A2. The average design temperature for the group is $15.7^{\circ} \mathrm{F}$. 
Table A-1 Population Weighted Average Space Heating Degree Days

(1)

(2)

Population of Vented Heaters

Census

Region

\begin{tabular}{lrrrr} 
Pacific & $3,672,950$ & 26.6 & 3820 & 1016 \\
Mountain & 649,618 & 4.7 & 5780 & 271 \\
East So. Cntrl. & $1,007,956$ & 7.3 & 3795 & 277 \\
So. Att. & $2,683,320$ & 19.5 & 3380 & 659 \\
W. No. Cntrl. & $1,179,377$ & 8.6 & 6825 & 587 \\
E. No. Cntrl. & $1,640,383$ & 11.9 & 6610 & 787 \\
Mid. Att. & 800,859 & 5.8 & 6100 & 354 \\
New Eng. & 369,041 & 2.7 & 6820 & 184 \\
W. So. Cntrl. & $1,783,762$ & 12.9 & 2350 & 303 \\
\hline
\end{tabular}

Total

$13,787,266$
(3) Regional Average Degree Days

4438
(4)

Population Weighted Degree Days 
Table A-2 Design Temperatures from 97 1/2\% Column of ASHRAE Handbook of Fundamentals (1972)

CITY

DESIGN TEMP

${ }^{\circ} \mathrm{F}$

DEGREE

DAYS

Charlestown, SC

14

4476

Huntington, WV

14

4446

Philadelphia, PA

15

4486

St. Louis, MO

4484

Albuquerque, NM

17

4348

Evansville, IN

10

4435

Bishop, CA

15

4275

Washington, DC

15

4551

Sandberg, CA

25

4209

Eureka, CA

35

4643

Prescott, $A Z$

15

4654

Dover, DE

12

4660

Louisville, KY

9

4620

Avg.

15.7 


\section{APPENDIX B}

Detailed Stepwise Procedure for Calculation of Annual

Efficiency for Heaters Equipped with Step-Modulating or Two-Stage Thermostat Controls 


\section{Appendix B}

Detailed Stepwise Procedure for Calculation of Annual Efficiency for Heaters Equipped with Step-Modulating

or Two-Stage Thermostat Controls

The first 11 steps deal with the calculation of minimum and maximum heat outputs, and fraction of time and outdoor temperature in each mode. Each of the following steps refers to a similarly numbered block in figure $\mathrm{B}-1$.

1. Enter the maximum fuel input rate (including fuel supply to pilot flame).

2. Enter the steady state efficiency at the maximum input rate (determined in accordance with the DuE test procedure).*

3. Calculate and enter the maximum heat output rate $=\frac{\text { Step } 1 \text { X Step } 2}{100}$.

4. Enter the minimum (reduced) fuel input rate (including fuel supply to pilot flame).

5. Enter the steady state efficiency at reduced fuel input rate (determined in accordance with the DoE test procedure).*

6. Calculate and enter the minimum heat output rate $=\frac{\text { Step } 4 \mathrm{X} \text { Step } 5}{100}$.

7. Calculate and enter ratio of minimum to maximum output

$$
\text { RATIO }=\frac{\text { Qut, } \text { min }_{\text {out } \max }}{\text { Qux }_{\text {outep } 6}} \text { or }
$$

8. Read the percentage of time in the low fire cycling mode ( $R$ ) from the graph of figure 7 for the minimum/maximum ratio corresponding to the ratio determined in step (7).

9. Calculate percentage of time in the non-cycling mode $\left(R_{h i}\right)$.

$$
\mathrm{R}_{h_{i}}=100-\mathrm{R}_{10}(\text { Step 8) }
$$

10, Read the average outdoor temperatures for the cycling and non-cycling 11. mode, $\mathrm{T}_{\text {}}$ and $\mathrm{T}_{\mathrm{O}}$ ' respectively, from figure 7 at the point corresponding to $\mathrm{min} / \mathrm{max}$ ratio determined in step ( 7 ).

In the next four steps, the average steady state efficiency and on-cycle infiltration losses for the non-cycling mode are determined.

*References 1 and 3 . 
12. Calculate and enter average steady state efficiency (\%) for the noncycling mode, "ns, hi

$$
n_{s s, h i}=\frac{n_{s s, \min }+n_{s s, \max }}{2} \text { or } \frac{\text { Step } 5+\text { step } 2}{2}
$$

13. Enter the on-period infiltration loss ( $\left.\mathrm{L}_{\mathrm{I}, \mathrm{ON}}, \mathrm{min}\right)$ at the minimum input rate (determined in accordance with the $\mathrm{D}_{\mathrm{OE}}$ test procedure for an outdoor temperature equal to $\mathrm{T}_{\text {oa' }}$ (Step 11).

14. Enter the on-cycle infiltration loss at the maximum input rate (determined in accordance with the DOE test procedure for an outdoor temperature equal to $\mathrm{T}_{\text {oa }}$, (Step 11).

15. Calculate and enter the average on-cycle infiltration loss (\%) for the non-cycling mode

$$
\mathrm{L}_{\mathrm{I}, \mathrm{ON}, \text { avg }}=\frac{\mathrm{L}_{\mathrm{I}, \mathrm{ON}, \text { min }}+\mathrm{L}_{\mathrm{I}, \mathrm{ON}, \mathrm{max}}}{2} \text { or } \frac{\text { Step } 13+\text { Step } 14}{2}
$$

The part load efficiency, $\eta_{11}$, for both the cycling and non-cycling modes are determined next, and the weighted average efficiencies are then calculated.

16. Calculate and enter the part load efficiency for the non-cycling mode

$$
\eta_{u, h i}=n_{s s, h i}\left(\text { Step 12)- } L_{I, O N, \text { av }}\right. \text { (Step 15) }
$$

17. Calculate and enter the percentage part load efficiency (\%) for the cycling mode:

$$
\eta_{\mathrm{u}, 10}=100-\mathrm{L}_{\mathrm{L}}-\frac{20}{\mathrm{t}_{\mathrm{ON}}+\mathrm{PFxt}_{\mathrm{OFF}}}\left(\mathrm{L}_{\mathrm{S}, \mathrm{ON}}+\mathrm{L}_{\mathrm{I}, \mathrm{ON}}+\mathrm{L}_{\mathrm{S}, \mathrm{OFF}}+\mathrm{L}_{\mathrm{I}, \mathrm{OFF}}\right)
$$

where the thermal losses are determined in accordance with the DOE orocedure for the minimum firing rate, at outdoor temperature equal to $\mathrm{T}_{\mathrm{Oa}}(\mathrm{Col} 10)$, and $\mathrm{t}_{\mathrm{ON}}=\mathrm{t}_{\mathrm{OFF}}=20 \mathrm{~min}$. Alternatively, $\mathrm{L}_{\mathrm{S}, \mathrm{OFF}}$ and $\mathrm{L}_{\mathrm{I}, \mathrm{OFF}}$ can be measured using the tracer gas technique [6]. "PF is the pilot fraction (the ratio of pilot input $Q_{p}$ to total fuel input $Q_{i n}$ ).

18. Calculate and enter the weighted average part load efficiency for the cycling and non-cycling modes

$$
\begin{aligned}
& \eta_{\mathrm{u}, \mathrm{wt}}=\mathrm{R}_{10} \times \eta_{\mathrm{u}, 10}+\mathrm{R}_{\mathrm{hi}} \mathrm{X} \eta_{\mathrm{u}, \mathrm{hi}} \\
& \text { or Step } 8 \times \text { step } 17+\text { Step } 9 \text {, step } 16
\end{aligned}
$$

Appendix B (cont) 
19. Calculate and enter the weighted average steady state efficiency for the cycling and non-cycling modes.

$$
n_{\text {ss,wt }}=R_{10} \times \eta_{\text {ss,min }}+R_{h i} \times n_{s s, h i} \text { or Step } 8 \times \text { step } 5+\text { step } 9 \times \text { Step } 12
$$

The annual fuel efficiency for modulating type heaters is finally calculated using the weighted efficiencies from steps 18 and 19.

$$
\text { 20. EHFYA }=\frac{n_{s s, w t} \times \eta_{11, w t} \times 4400}{n_{s s, w t} \times 4400+2.5 \eta_{u, w t} \times \text { PF } \times 4600}
$$

Procedure for Calculating Annual Efficiency for Heaters with Two-Stage Controls

The calculations listed above for heaters with step-modulating controls will, with slight modification, accommodate heaters with two-state controls. The modifications are as follows:

- replace step (12) with the equality: $\eta_{s s, h i}=\eta_{s s, \max }$

o delete steps (13) through (15), and

- replace step (16 with a calculation similar to that of step (17 but for the maximum input rate and an outdoor temperature equal to Toa'.

The annual fuel efficiency given by step (20) will then be for a heater with two-stage contol. 

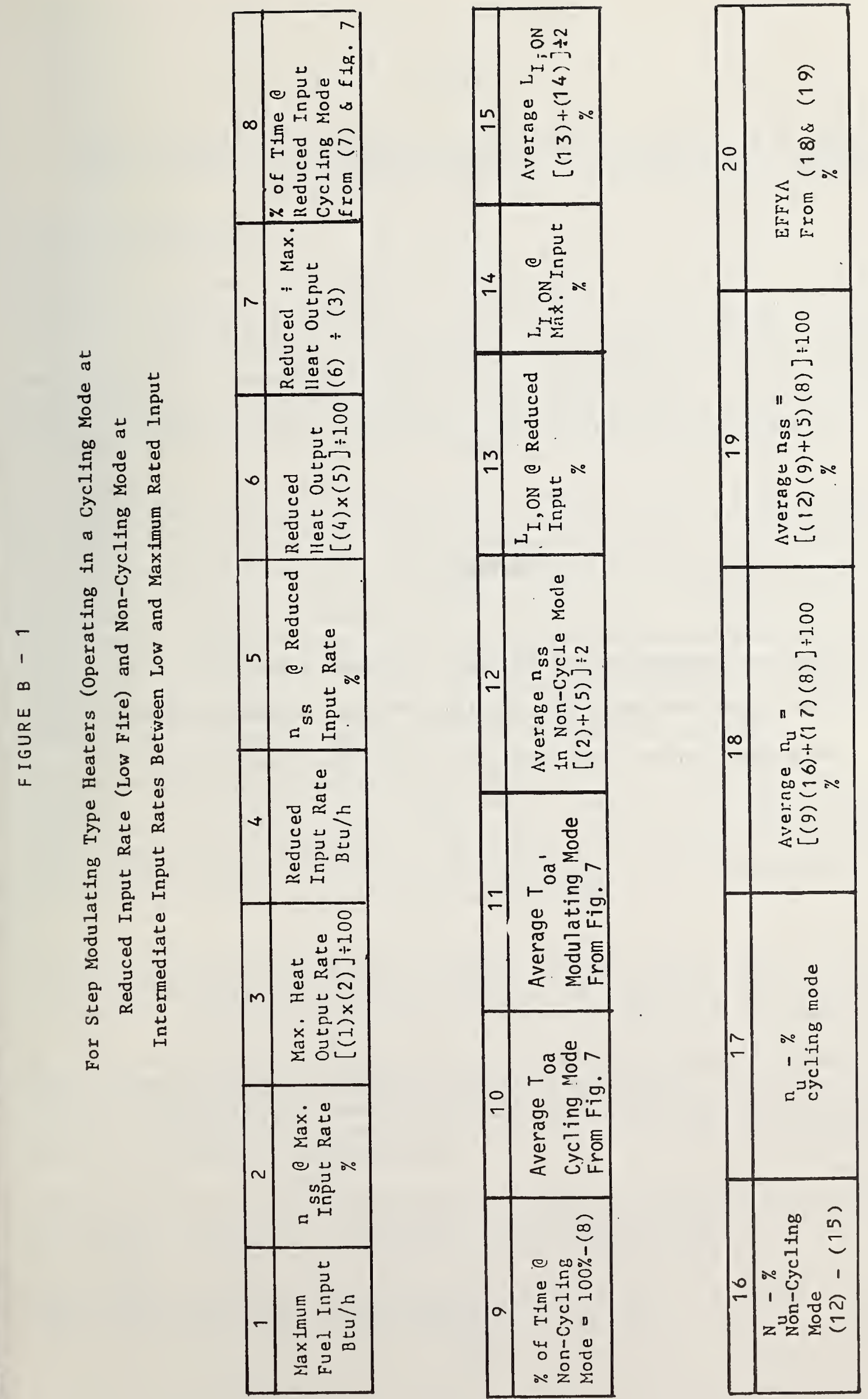


\section{APPENDIX C}

Computer Program for the Evaluation of Annual Fuel Utilization Efficiency and Energy Consumption of Vented Heating Equipment With Single-Stage, Two-Stage, and Step-Modulating Thermostats 
Computer Program for the Evaluation of Annual Fuel Efficiency of Heating Equipment With Single-Stage, Two-Stage, and Step-Modulating Control

\section{Program Description}

The computer program to be described here is based on the original program NBSFBS5 developed in 1978 by Kelly, et al [2]. While maintaining the previous structure of NBSFBS5, the present program handles heating equipment with singlestage, two-stage, and step-modulating input, and permits the use of tracer gas measurements in determining off-cycle losses (see Reference). The computer program consists of a main program, entitled FBVH, and four subroutines: SENLOS, * WEIGHT, OFFLOS, and FUNT4. It is written in ASCII Fortran and should be compatible with most Fortran $V$ processors with a minimum of change.

The main program FBVH, as its predecessor, chooses calculation paths, makes appropriate calls to subroutines, and performs calculation steps based on input information. The theoretical calculations and the order in which the calculations proceeds are essentially the same as in NBSFBS5. For single-stage controls, a straight-through path, identical to that in NBSFBS5, is taken. For step-modulating and two-stage controls, outdoor temperatures and time in each mode are determined via a call to NEIGHT, and two passes through the calculation stream are then taken. In the first pass, input data for the maximum firing rate and outdoor temperature $\mathrm{T}_{\mathrm{oa}}$, are used. In the second pass, required parameters are saved, and data for the minimum firing rate and outdoor temperature $\mathrm{T}_{\mathrm{oa}}$, are used. Weighted efficiencies are calculated in accordance with section 3.2 .

Subroutine SENLOS determines values for steady state: latent heat loss $\mathrm{L}_{\mathrm{L}}$, sensible heat loss $\mathrm{L}_{\mathrm{S}}, \mathrm{ON}, \mathrm{ss}$, and steady state efficiency ${ }_{\mathrm{SS}}$ as well as other parameters. This SENLOS version contains the stack to flue mass flow ratio S/F (SFR) computed from stoichiometric relationships and is used in place of the input value of SFR for all calculations (the computed value was previously used only if it was greater than the input value of SFR).

Subroutine WEIGHT assigns values for average outdoor temperatures in the cycling and non cycling modes ( $\mathrm{T}_{\mathrm{Oa}}$ and $\mathrm{T}_{\mathrm{o}}$ ' respectively), and the fraction of time in the cycling mode. WEIGHT is called only for step-modulating and two-stage heaters.

The subroutine OFFLOS calculates off-cycle sensible heat and infiltration losses based on the tracer gas technique described in Reference 6, For this calculation, which is optional, twenty measurements of tracer concentration in stack gas are required at one-minute intervals, along with the initial tracer concentration, and tracer gas flow rate and temperature.

Subroutine FUNT 4 calculates functions required for the analytical determination of off-cycle stack losses (the current DOE and default means of calculating offcycle losses). FUNT 4 is unchanged from the NBSFBS5 version.

*SENLOS used in this procedure is modified from another form of the

SENLOS given in Reference 2 with NBSFBS5. 
A flow chart of $\mathrm{FBVH}$ including corresponding statement numbers from the program listing, is shown in figure Cl. This figure does not include all program details but only those essential differences between FBVH and NBSFBS5. The majority of the theoretical calculations are performed in statements 132 through 256 and are described in detail in Reference 4. The complete program listing, with subroutines, is shown in figure $\mathrm{C} 2$.

\section{Input Data Format}

The input data file or element for FBVH must be consistent with the format shown in figure C3. A sample data form is presented as figure C4 for comparison. It should be noted that when ICTRL and LOSOPT are selected such that some lines in figure C3 are omitted in the data file, blank lines should not be inserted; the line numbers in the data file will therefore differ from those in figure c3 in certain cases.

\section{Sample Input and Output}

Sample sets of computer program output for a heater with a step-modulating and with a two-stage control are presented in figures $\mathrm{C} 4$ and $\mathrm{C5}$ respectively. 
Figure Cl. Flow chart of main program, FBVH

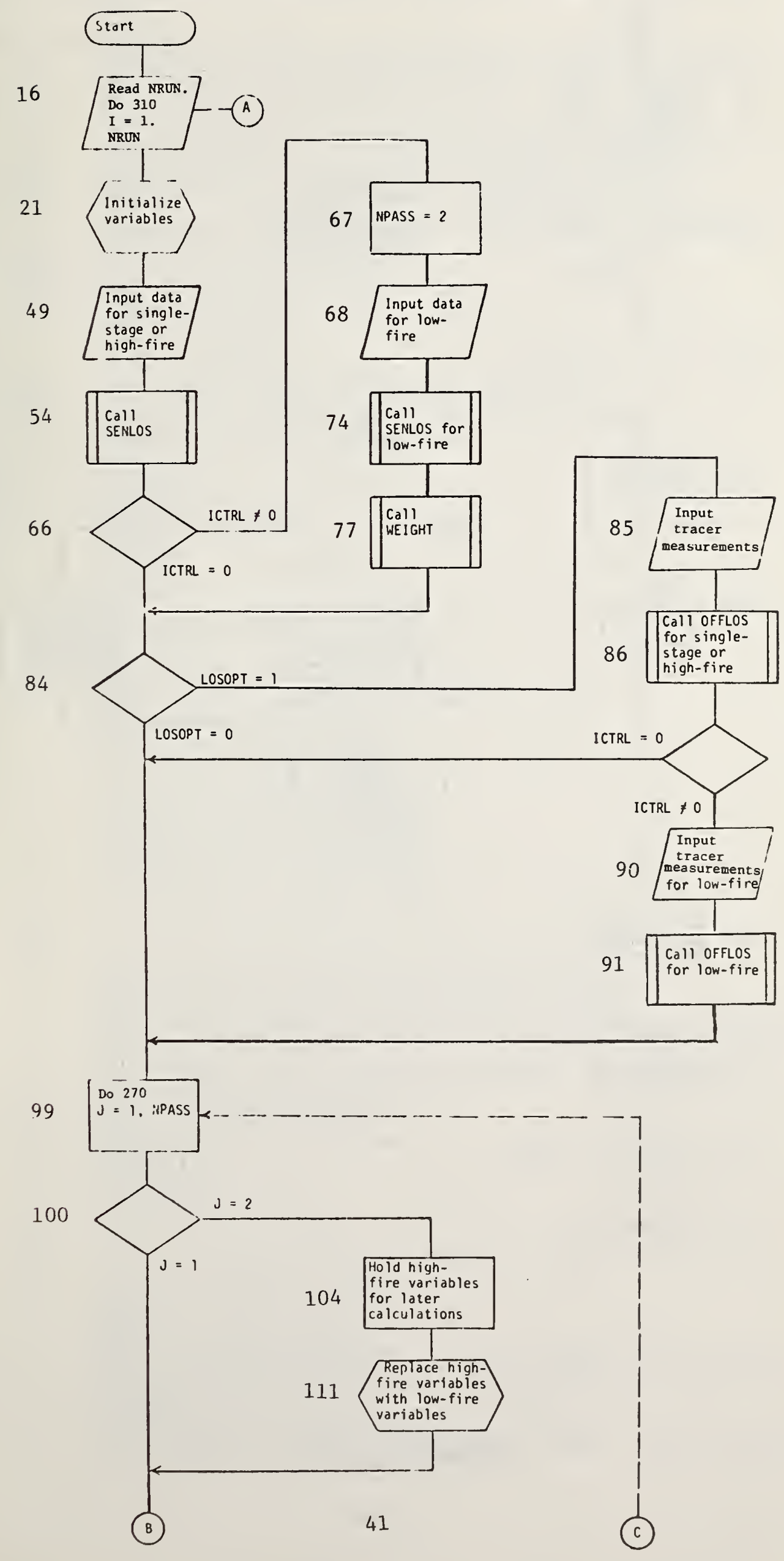




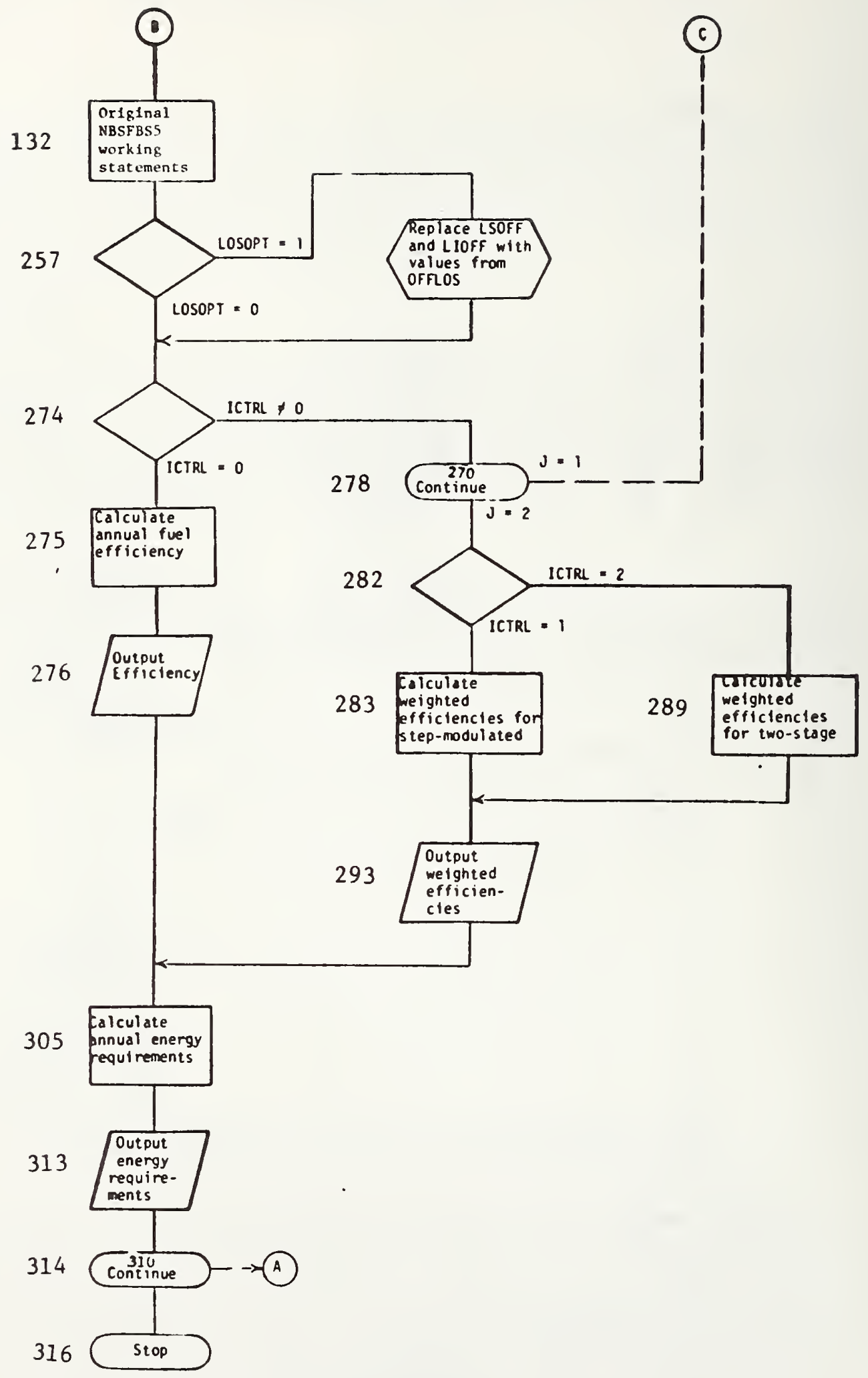

Figure Cl (cont) 
Figure C2. Main program and subroutine listings; main program FBVH

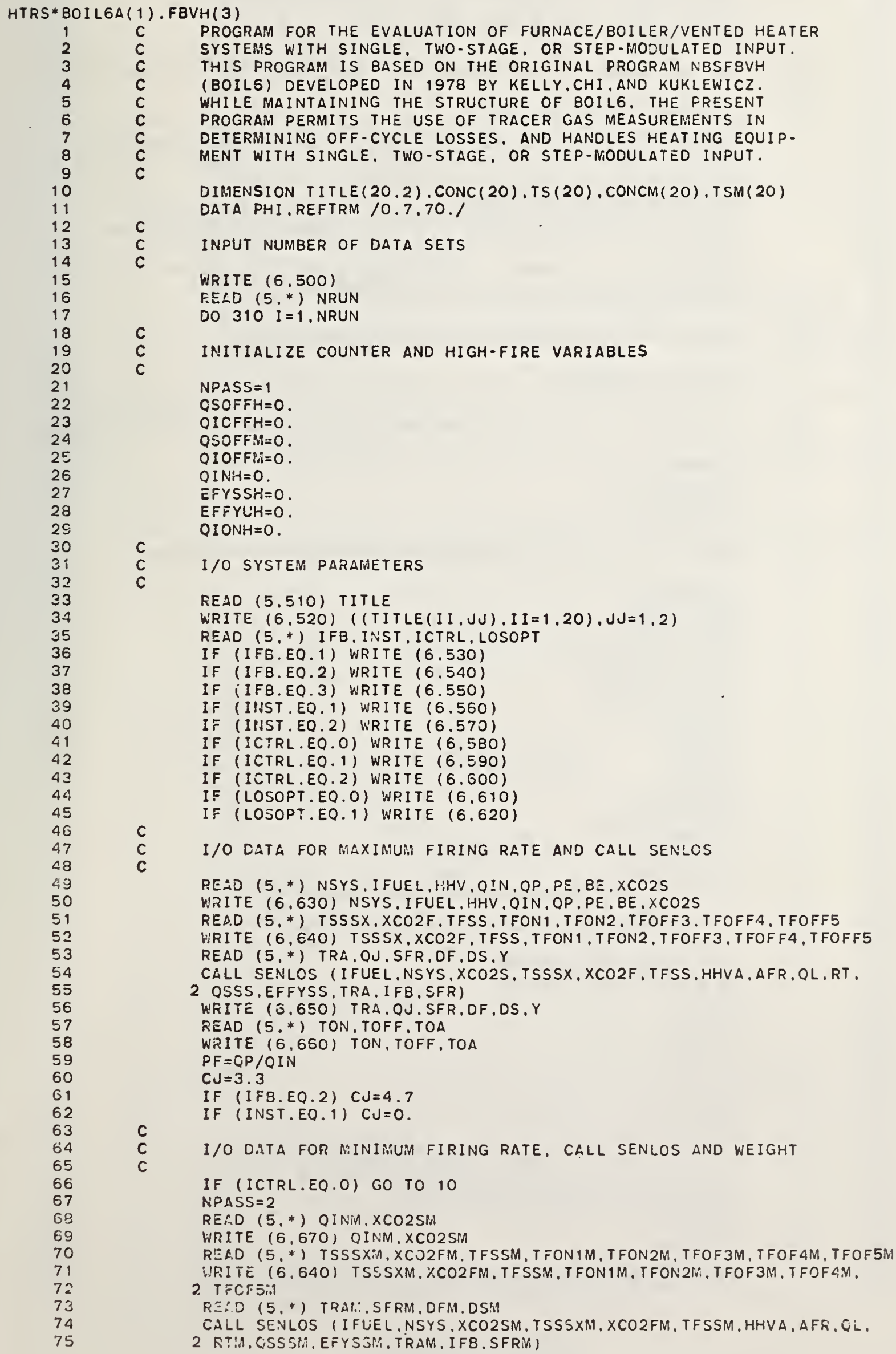


WRITE $(6,680)$ TRAM,SFRM.DFM.DSM

CALL WEIGHT (QIN, EFFYSS.OINM,EFYSSM.RLOW, TOALO, TOAHI)

RHIGH $=1$. - RLOW

W'RITE (6.69O) RLOW, RHIGH,TOALO,TOAHI

$T O A=T O A H I$

I/O TRACER GAS DATA AND CALCULATED OFF-CYCLE LOSS IF LOSOPT $=1$

10

IF (LOSOPT.EO.O) GO TO 20

FEAD $(5, *)(\operatorname{CONC}(J), T S(J), J=1,20)$, CONCI , VTTT, TROOM

CALL OFFLOS (CONC, TS, CONCI, VTTT, TROCM, TOA, QIN, OSOFFH, QIOFFH)

HRITE $(6,700)(\operatorname{CONC}(J), J=1,10),(T S(J), J=1,10),(\operatorname{CONC}(J), J=11,20)$,

2 (TS (J), J $=11,20)$, CONCI.VTTT, TROOM, QSOFFH, OIOFFH

IF (ICTRL.EQ.O) GO TO 20

READ $(5, *)(\operatorname{CONCM}(J), \operatorname{TSM}(J), J=1,20), \operatorname{CONCIM}, \operatorname{VTTTM}$, TROOMM

CALL OFFLOS (CONCM.TSM. CONCIM, VTTTM. TROOMM. TOALO. QINM, QSOFFM. 2 OIOFFM)

WRITE $(6,710)(\operatorname{CONCM}(J), J=1,10),(\operatorname{TSM}(J), J=1,10),(\operatorname{CONCM}(J), J=11,20)$

2 . (TSM(J), J $=11,20)$, CONCIM, VTTTM, TROOMI, OSOFFM, QIOFFM

20 WRITE $(6,720)$

C

LOOP THRU BOILG WORKING CALCULATIONS NPASS TIMES

DO $270 \mathrm{~J}=1$. NPASS

IF (J.EQ.1) GO TO 30

$c$
$c$

C

C

\section{HOLD NECESSARY VARIABLES FOR MODULATING AND TWO STAGE CALCULATIONS}

QINH:= QIN

EFYSSH $=$ EFFYSS

EFFYUH $=E F F Y U$

QIONH=QION

\section{REPLACE MAXIMUM FIRE VARIABLES WITH MINIMUM FIRE VARIABLES}

QIN=QINM

TFSS $=$ TFSSM

TFON $1=$ TFON1M

TFON2 $=$ TFON2M

TFOFF $3=$ TFOF $3 M$

TFOFF $4=$ TFOF $4 M$

TFOFF5 $=$ TFOF $5 M$

TRA $=$ TRAM

$S F R=S F R M$

$D F=D F M$

$D S=D S M$

$R T=R T M$

QSSS $=$ QSSSM

EFFYSS $=$ EFYSSIA

TOA $=$ TOALO

WRITE (6.730)

REFTOA $=$ TOA

WRITE (6,740) PF, HHVA, AFR, QL, CU,RT, QSSS, EFFYSS

c

*** COLUMNS 31 THROUGH 43 IN NBSIR 78-1543***

$T S S S=(T F S S-T R A) / S F R+T R A$

IF (IFB.EQ.2) GO TO 40

$C_{1}=2$

$\mathrm{C} 2=0.5$

$\mathrm{C} 3=7.5$

$C 4=1.5$

GO TO 50

$\mathrm{C} 1=4.5$

$\mathrm{C} 2=1$.

C $3=18.75$

$C 4=3.75$

50

IF (TFSS.EQ.TFON1. AND.TFSS.EQ.TFON2) GO TO 60

TAON $=$ C1/ALOG ( (TFSS - TFON1)/(TFSS-TFON2) )

ZETFOX $=($ TFSS - TFON1 $) * E X P(C 2 / T A O N)$

60 GO TO 70

70

$T A O N=0$. ZETFOX $=0$.

CONTINUE

TAOFF $=$ C $3 / A L O G($ (TFOFF3 - TFOFF5) / (TFOFFA - TFOFF5 ) )

Figure C2 (cont) 


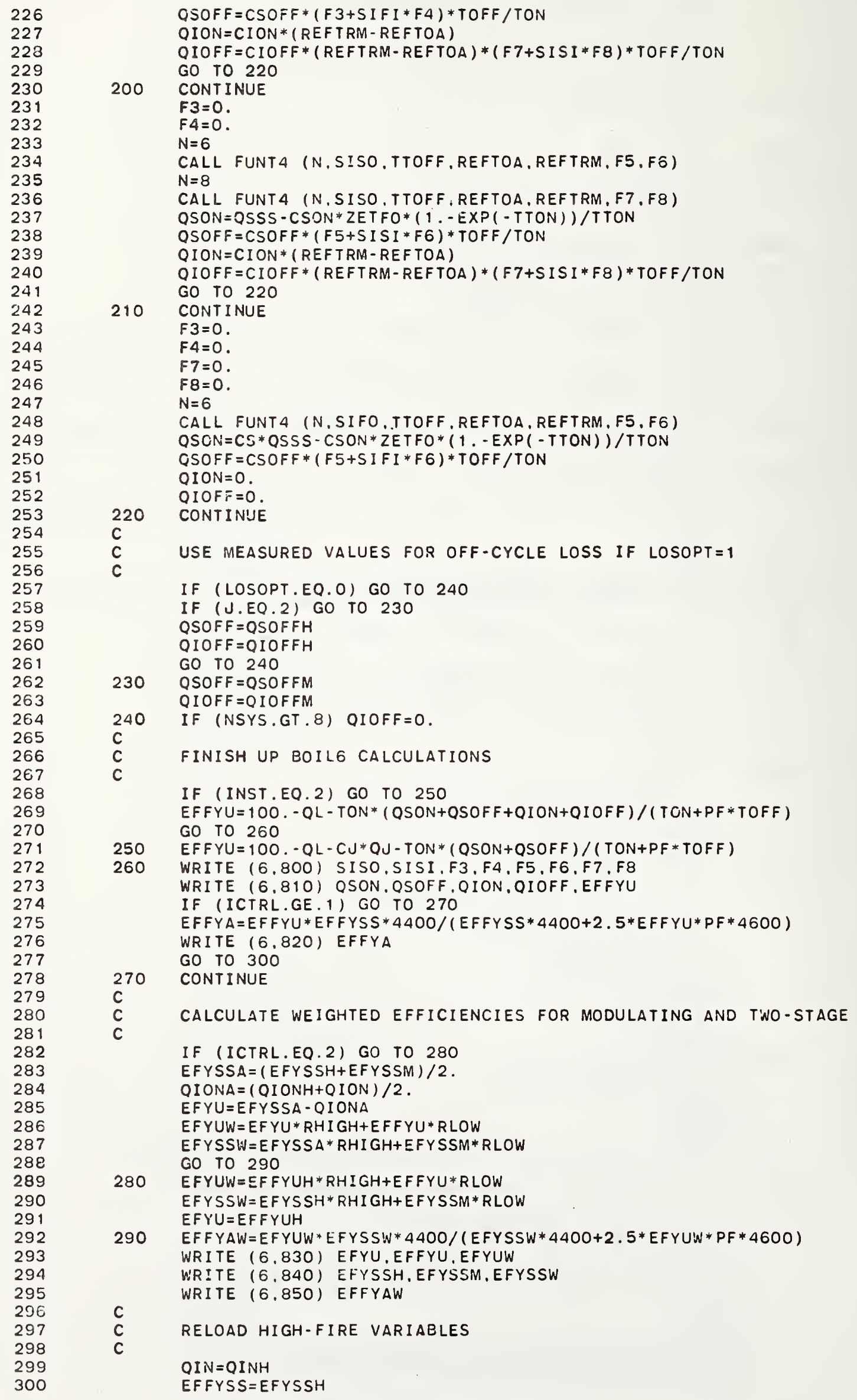

QSOFF $=$ CSOFF* $(F 3+S I F I * F 4) * T O F F / T O N$

QION=CION* (REFTRM-REFTOA)

QIOFF $=$ CIOFF* $($ REFTRM-REFTOA $) *(F 7+S I S I * F 8) * T O F F / T O N$

200

GO TO 220

CONT INUE

$F 3=0$.

$F 4=0$.

$N=6$

CALL FUNTA (N,SISO, TTOFF, REFTOA, REFTRM, F5, F6)

$N=8$

CALL FUNT4 (N,SISO, TTOFF, REFTOA, REFTRM, F7, F8)

QSON $=$ QSSS - CSON*ZETFO* (1. - EXP $(-$ TTON ) )/TTON

QSOFF $=$ CSOFF* $(F 5+S I S I * F 6) *$ TOFF/TON

QION=CION*(REFTRM - REFTOA)

QIOFF $=$ CIOFF * $($ REFTRM - REFTOA $) *(F 7+S I S I * F 8) * T O F F / T O N$

GO TO 220

210 CONTINUE

$\mathrm{F} 3=0$.

$F 4=0$.

$F 7=0$.

$\mathrm{F} 8=0$.

$N=6$

CALL FUNT4 (N,SIFO, TTOFF, REFTOA, REFTRM, F5, F6)

QSCN $=$ CS*QSSS - CSON*ZETFO* $(1$. - EXP $(-$ TTON $)) /$ TTON

QSOFF $=$ CSOFF* $(F 5+S I F I * F G) *$ TOFF /TON

QION $=0$.

QIOFF $=0$.

220 CONTINUE

c

C USE MEASURED VALUES FOR OFF-CYCLE LOSS IF LOSOPT $=1$

c

IF (LOSOPT.EQ.O) GO TO 240

IF (J.EQ.2) GO TO 230

QSOFF $=$ QSOFFH

QIOFF $=$ QIOFFH

GO TO 240

$230 Q S O F F=Q S O F F M$

$Q I O F F=Q I O F F M$

240 IF (NSYS.GT.8) QIOFF=0.

c

C

FINISH UP BOILG CALCULATIONS

IF (INST.EQ.2) GO TO 250

EFFYU $=100 .-Q L-T O N *(Q S O N+Q S O F F+Q I O N+Q I O F F) /(T O N+P F * T O F F)$ GO TO 260

250 EFFYU $=100 .-Q L-C J * Q J-T O N *(Q S O N+Q S O F F) /(T O N+P F * T O F F)$

260 WRITE $(6,800)$ SISO,SISI,F3,F4,F5,F6,F7,F8

WRITE $(6.810)$ QSON. OSOFF.QION, QIOFF, EFFYU

IF (ICTRL.GE.1) GO TO 270

EFFYA $=E F F Y U * E F F Y S S * 4400 /($ EFFYSS*4400+2.5*EFFYU*PF*4600)

WRITE $(6.820)$ EFFYA 270 CONTINUE

C
C

CALCULATE WEIGHTED EFFICIENCIES FOR MODULATING AND T'NO-STAGE

IF (ICTRL.EQ.2) GO TO 280

EFYSSA $=($ EFYSSH+EFYSSM $) / 2$.

QIONA $=($ QIONH+QION $) / 2$.

$E F Y U=E F Y S S A-Q I O N A$

$E F Y U W=E F Y U * R H I G H+E F F Y U * R L O W$

EFYSSW $=$ EFYSSA*RHIGH+EFYSSM*RLOW

GO TO 290

280 EFYUW $=$ EF FYUH*RHIGH+EFFYU*RLOW

EFYSSW $=E F Y S S H * R H I G H+E F Y S S M * R L O W$

$E F Y U=E F F Y U H$

290 EFFYAW=EFYUW*EFYSSW* 4400/(EFYSSW*4400+2.5*EFYUW*PF*4600)

WRITE $(6,830)$ EFYU.EFFYU. EFYUW

WRITE (6.840) EFYSSH. EFYSSM.EFYSSW

WRITE $(6,850)$ EFFYAW

c
C
C

RELOAD HIGH-FIRE VARIABLES

QIN $=$ QINH

EFFYSS=EFYSSH

Figure C2 (cont) 
$B=2 . * A * Q P * E F F Y U / 100000$.

IF (QP. LT.O.1) $8=0$.

$C=0.38$

DHR $=E F F Y S S * Q I N / 100000$

$80 \mathrm{H}=2080 . *(A * C * D H R-8)$

$\triangle F U E L=(Q I N-Q P) * 80 \mathrm{H}+8760,{ }^{*} Q P$

$\triangle E L E C=(P E+Y * B E) * 8 O H$

W'RITE $(6,860)$ AFUEL, AELEC

CONTINUE

WRITE $(6,870)$

STOP

C

C

\section{FORMAT STATEMENTS}

FORMAT (/5X,31HINPUT DATA - @ADD FILE.ELEMENT/)

FORMAT (20A4)

FORMAT $(/ / 2(5 \times, 20 A 4 /))$

FORMAT ( $/ 5 X$.7HFURNACE)

FORMAT $(/ 5 X, 6 H B O I L E R)$

FORMAT ( $/ 5 X, 13$ HVENTED HEATER)

FORMAT ( $5 X, 16$ HINSTALLED INDOOR)

FORIMAT (5X,17HINSTALLED OUTDOOR)

FORMAT ( $5 X, 1$ EHSINGLE STAGE INPUT)

FORIIAT (5X,2OHSTEP MODULATED INPUT)

FORMAT ( $5 X, 15$ HTWO STAGE INPUT)

FORMAT ( $5 X, 3$ OHASSIGNED VALUES FOR OFF-LOSSES)

FORMAT ( $5 X, 3 O H M E A S U R E D$ VALUES FOR OFF-LOSSES)

FORMAT (///5X,13HINPUT VALUES //5X,6H1)NSYS4X,7H2) IFUEL $3 X$.

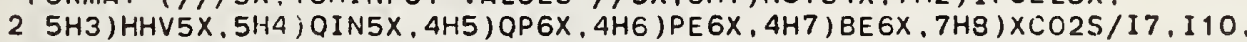

$36 \times, 8(1 P E 10.2))$

640 FORMAT (/5X,6H9)TSSS $4 X, 8 H 10) X C O 2 F 2 X .7 H 11)$ TFSS $3 X .8 H 12)$ TFON $12 X$.

28 H13)TFON22X, 9H14)TFOFF31X,9H15) TFOFF 41X,9H16)TFOFF5/3X.

$38(1 P E 10.2))$

650

FORMAT $(/ 5 X$

660

28 SH2 /3X.8(1PE10.2))

FORMAT (///5X,47HADDITIONAL INPUT VALUES FOR MINIMIM FIRING RATE//

$25 X, 6 H 1$ ) NSYS $4 X, 7 H 2$ ) I FUE L $3 X, 5 H 3$ ) HHV $X X, 5 H 4$ ) Q IN5X, 4H5) QP $5 X, 4 H 5$ ) PE6X,

$34 \mathrm{H} 7) \mathrm{BE} 6 \mathrm{X}, 7 \mathrm{HB}) \mathrm{XCO2S/3}(7 \mathrm{X}, 3 \mathrm{H} \cdots), 3 \mathrm{X}, 1 \mathrm{PE} 10,2,4 \mathrm{X}, 3 \mathrm{H} \cdots . .2(7 \mathrm{X}, 3 \mathrm{H}-\cdots)$.

$43 X, 1$ PE 10.2)

680 FORMAT $(/ 5 X, 6 H 17)$ TRA $4 X, 5 H 18)$ QJ5X,6H19)S/F $4 X, 5 H 20)$ DF $5 X, 5 H 21)$ OS, $5 X$,

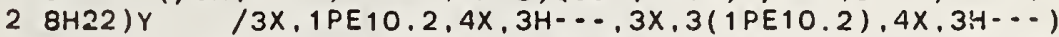

690 FORMAT (//5X,49HFRACTION OF TIME IN LOW FIRE/CYCLING MODE

2 F5.3/5X, 49HFRACTION OF TIME IN HIGH FIRE/NON-CYCLING MODE $=$ F5.3\%

$35 X, 40 H O U T D O O R$ AIR TEMP FOR CYCLING MODE

$=F 6.2 / 5 X$

700

4 4OHOUTDOOR AIR TEMP FOR NON-CYCLING MODE $=F 6.2$ )

FORMAT (///5X,22HFLUE LOSS MEASUREMENTS//

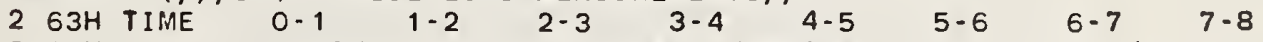

$313 \mathrm{H}$ 8-9 9-10/6H CONC $10(1 X, F 6.1) / 6 \mathrm{H}$ TEMP $10(1 X, F 6.1) / /$

$463 \mathrm{H}$ TIME $10-11 \quad 11-12$ 12-13 $13-14 \quad 14-15 \quad 15-16 \quad 16-17 \quad 17-18$

$513 \mathrm{H} 18-19$ 19-20/6H CONC $10(1 \mathrm{X}, \mathrm{F} 6,1) / 6 \mathrm{H}$ TEMP $10(1 \mathrm{X}, \mathrm{F} 6.1) / / 5 \mathrm{X}$.

626 HINITIAL CONC(ENTRATION) $=1 \mathrm{PE} 10.2 / 5 \mathrm{X}$.

727 HMETER VOLUME/BU8BLE TIME $=1$ PE $10.2 / 5 \mathrm{X}$

8 24HTEST ROOM TEMPERATURE $=1$ PE $10.2 / / 5 \mathrm{X}$.

917 HQSOFF MEASURED $=1 P E 10.2 / 5 X, 17$ HQIOFF MEASURED $=1 P E 10.2)$

FORMAT $(/ / 5 X, 19 H M I N I M U M$ FIRE VALUES//

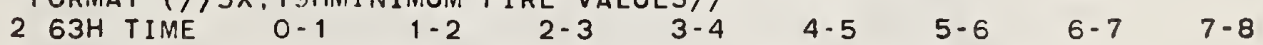

$313 \mathrm{H} 8-9$ 9-10/6H CONC $10(1 \times, F 6.1) / 6 H$ TEMP $10(1 \times, F 6.1) / /$

$463 \mathrm{H}$ TIME $10-11 \quad 11-12 \quad 12-13 \quad 13-14 \quad 14-15 \quad 15-16 \quad 16-17 \quad 17-18$

5 i $3 \mathrm{H} \mathrm{18-19}$ 19-20/6H CONC $10(1 \mathrm{X}, \mathrm{FG}, 1) / 6 \mathrm{H}$ TEMP $10(1 \mathrm{X}, \mathrm{F6}, 1) / / 5 \mathrm{X}$.

626 HINITIAL CONC(ENTRATION) $=1$ PE $10.2 / 5 X$.

7 27HMETER VOLUNE/BUBELE TIME = 1 PE $10.2 / 5 \mathrm{X}$.

8 24HTEST ROOM TEMPERATURE $=1$ PE $10.2 / / 5 X$.

$91 \%$ HQSOFF MEASURED $=1$ PE10.2/5X.17HOIOFF MEASURED $=1$ PE10.2) FORIAAT (///5X,18HCALCULATED VALUES-/)

FORIAT (///5X, 4OHCALCULATED VALUES - MINIMUM FIRING RATE/)

740 FORIIAT ( $/ 5 X, 5 H 23)$ PF5X,7H24)HHVA3X,6H25)A/F.7X,5H26) Q $-5 X, 5 H 27)$ CU5X,

25 H23)RT5X,7H29) OSSS $3 X, 9 H 30)$ EFFYSS $/ 3 X, 8(1$ PE10.2))

FORMAT $(/ 5 X, 7 H 3\}$ iTSSS $3 X, 8 H 32$ ) TAUON $2 X, 9 H 33)$ ZETFOX $1 X, 9 H 34)$ TAUOFF, $1 X$, 2 9H35)PSIFOX 1 X.9H36) PSIFIX 1 X, 9H37) PSISIX 1 X.9H3E)PSISOX/3X. 
3 B(IPEIO.2) )

760 FOR!Ai $(/ 5 X .5 H 39) C S 5 X .7 H 40) C S O N 3 X, 8 H 41) C S O F F 2 X, 7 H 42) C I O N 3 X$. 28 B 43 )CIOFF/3X.5(1FE10.2))

770 FORMAT $\left(/ / / 5 X, 46 H^{*} * *\right.$ WARNING-HEATING VALUE OF TEST FUEL IS TOO 2 THLOW $* * * / / / 1)$

780 FORHAT (///5X.4GH*** WARNING-HEATING VALUE OF TEST FUEL IS TOO . $28 \mathrm{HHICH} * * * / / / 1$

790 FORIAT ( $/ 5 X, 6 H 44)$ TOA $4 X .6 H 45)$ TON $4 X, 7 H 46)$ TOFF $3 X, 7 H 47)$ T TON3X, 2 8H48)TTOFF, 2X,8H49)ZETFO2X,8H50)PSIFO2X,8H51)PSIFI/3X.

$38(1 F E 10.2))$

800 FORWAT ( $/ 5 X$. QH52)PSISO2X.8H53)PSISI 2 X.5H54)F35X.5H55)F45X. $25 H 56$ )F $55 X .5 H 57$ ) F 65X.5H58) F 75X.5H59)F8/3X,8(1PE 10.2))

810 FORMAT (/5X,7H6O)QSON3X.8H61) QSOFF $2 X .7 H 62)$ QION.3X.8H63) QIOFF $2 X$. 28 H64)EFFYU/3X.5(1PE 10.2))

820 FORMAT ( $/ / / 5 X, 25$ HANNUAL FUEL EFFICIENCY = F5.2)

830 FORMAT (///5X.3SHFART-LOAD EFFICIENCY - HIGH FIRE $=F 6.2 / 5 X$. 235 HPART-LOAD EFFICIENCY - LOW FIRE = F6.2/5X.

3 4 OHWEIGHTED \&VERAGE PART - LOAD EFFICIENCY = F6.2)

840 FORMAT ( $/ 5 X .39 H S T E A D Y-S T A T E$ EFFICIENCY - HIGH FIRE $=F 6.2 / 5 X$. 23 3HSTEADY-STATE EFFICIEHCY - LOW FIRE $=F 6.2 / 5 X$.

3 43 HWEIGHTED AVERAGE STEADY-STATE EFFICIENCY = FG.2)

850 FORMAT ( 5 X , 42HWEIGHTED AVERAGE ANNUAL FUEL EFFICIENCY = F6.2)

860 FORMAT ( $5 \times, 33$ HANNUAL FUEL ENERGY CONSUMPTION $=1 \mathrm{PE} 10.3 .1 \times .3 \mathrm{HBTU} /$ $25 \times$.39HANNUAL ELECTRICAL ENERGY CONSUMPTION = 1 PE10.3, 1X.3HBTU)

870 FORMAT (///5X, 16HPROGRAM COMPLETE//) END

\section{Subroutine WEIGHT}

HTRS * BOILGA (1) , WE I GHT ( 3)

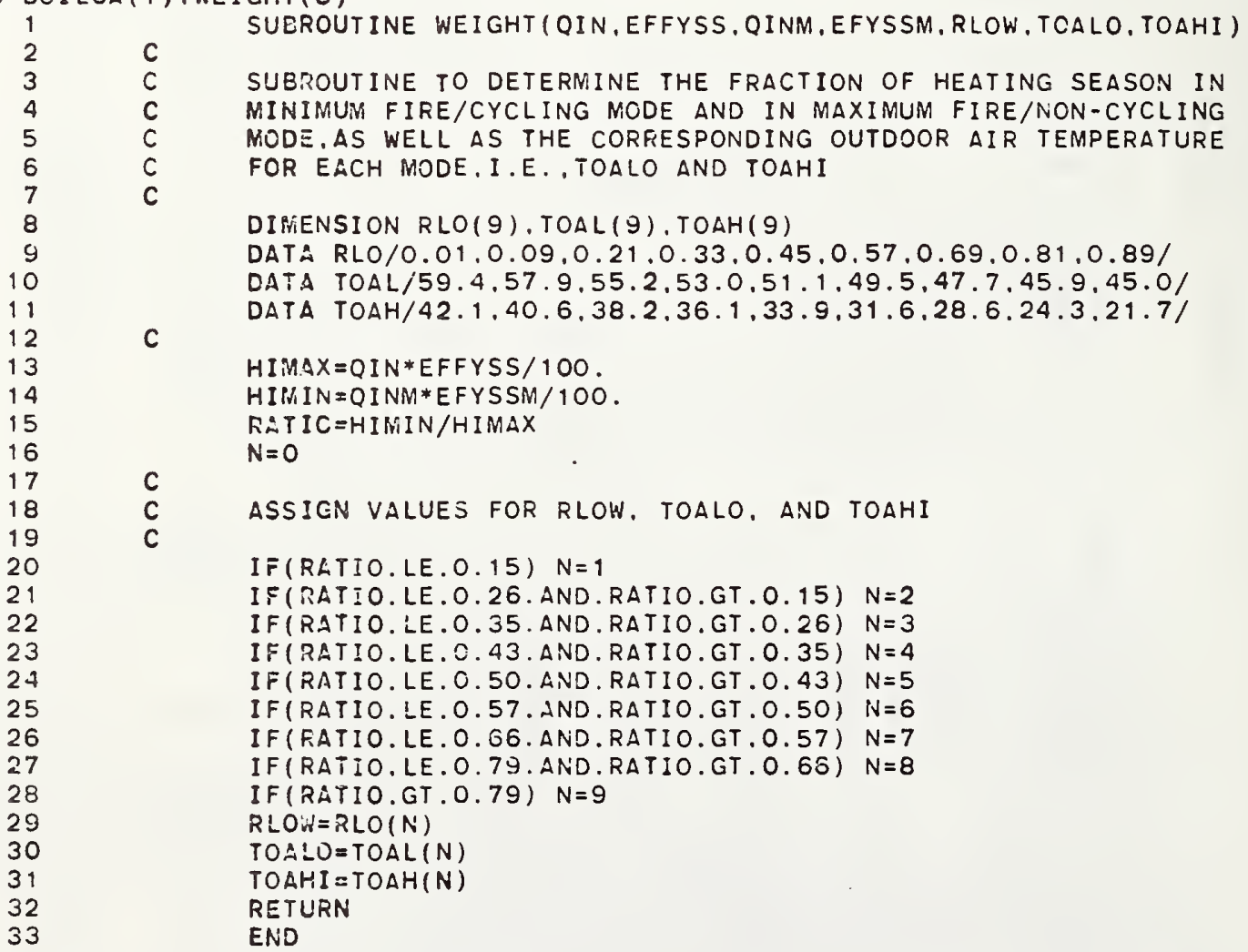

Figure C2. (cont) 
HTRS* BOILGA (1) . SENLOS(1)

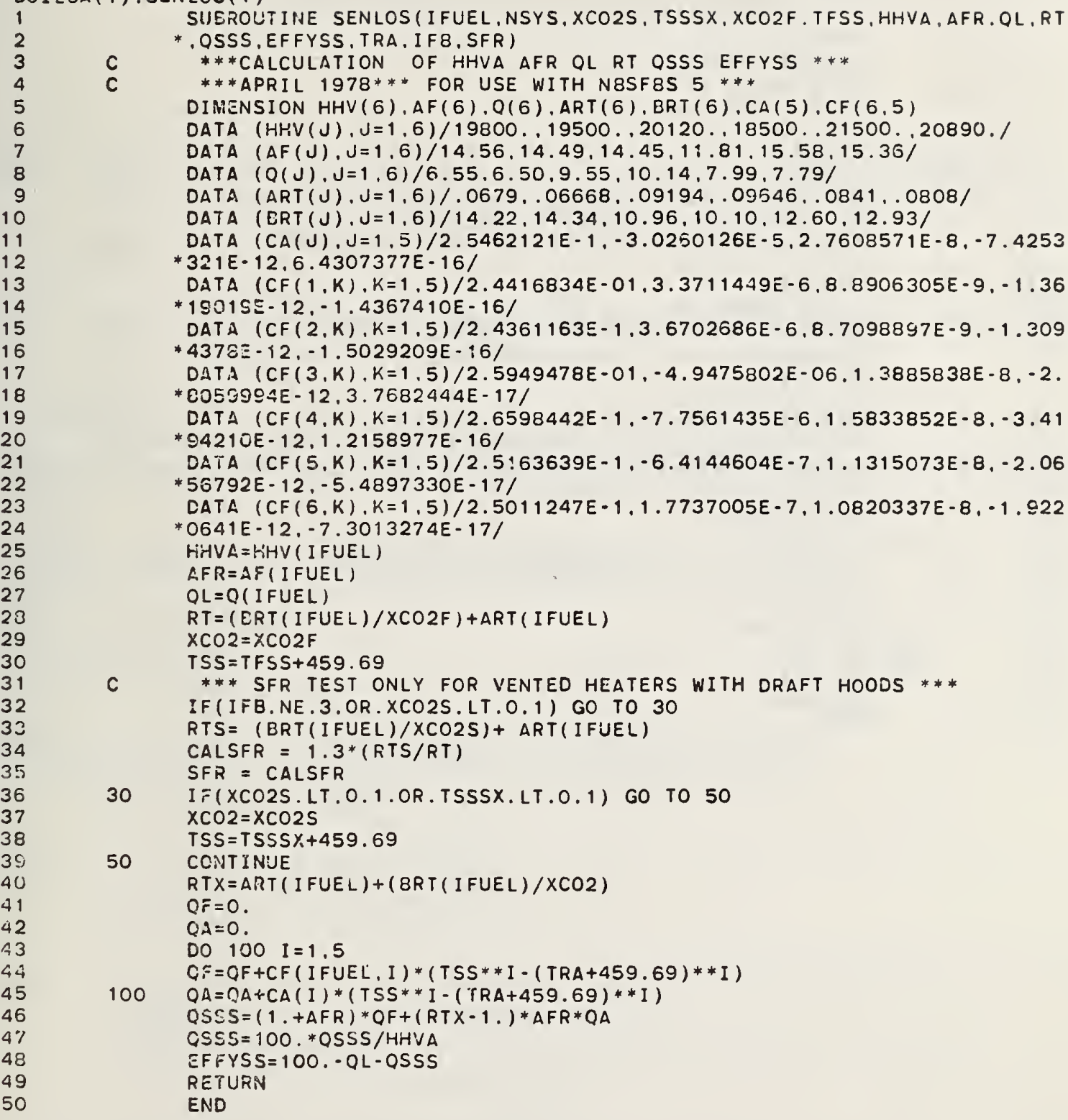

Subroutine OFFLOS

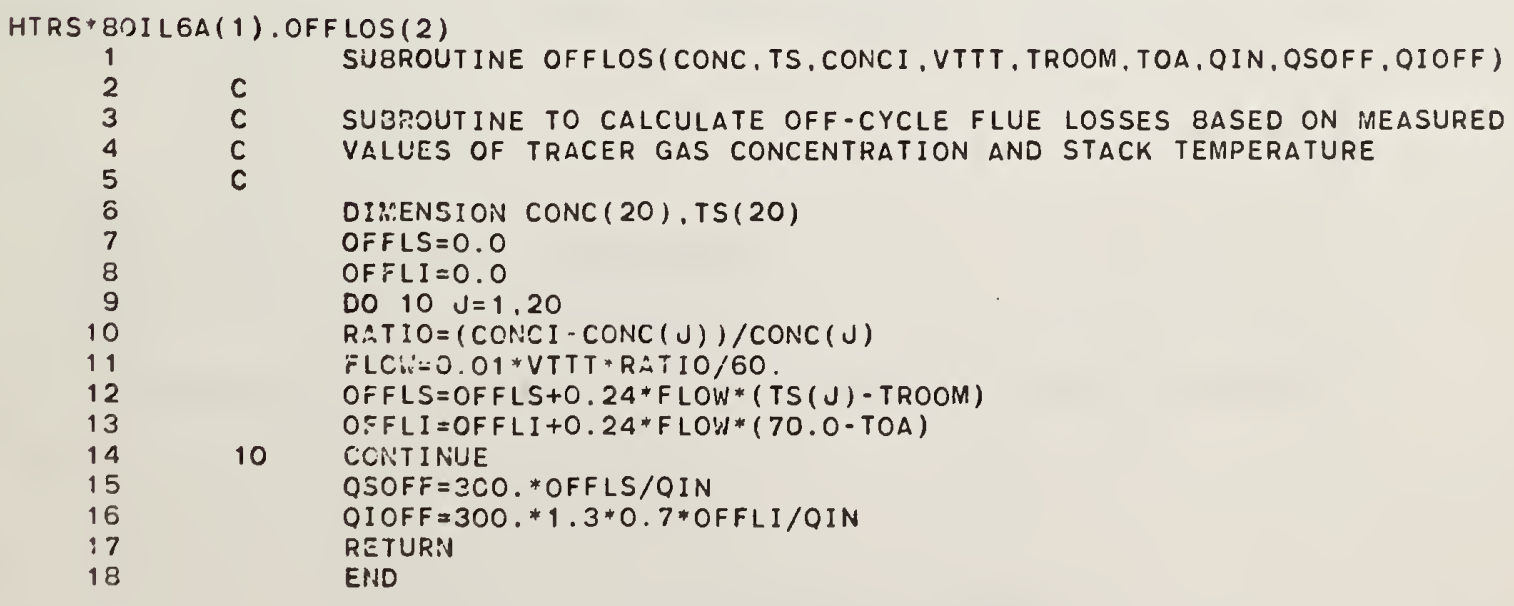

Figure C2 (cont) 


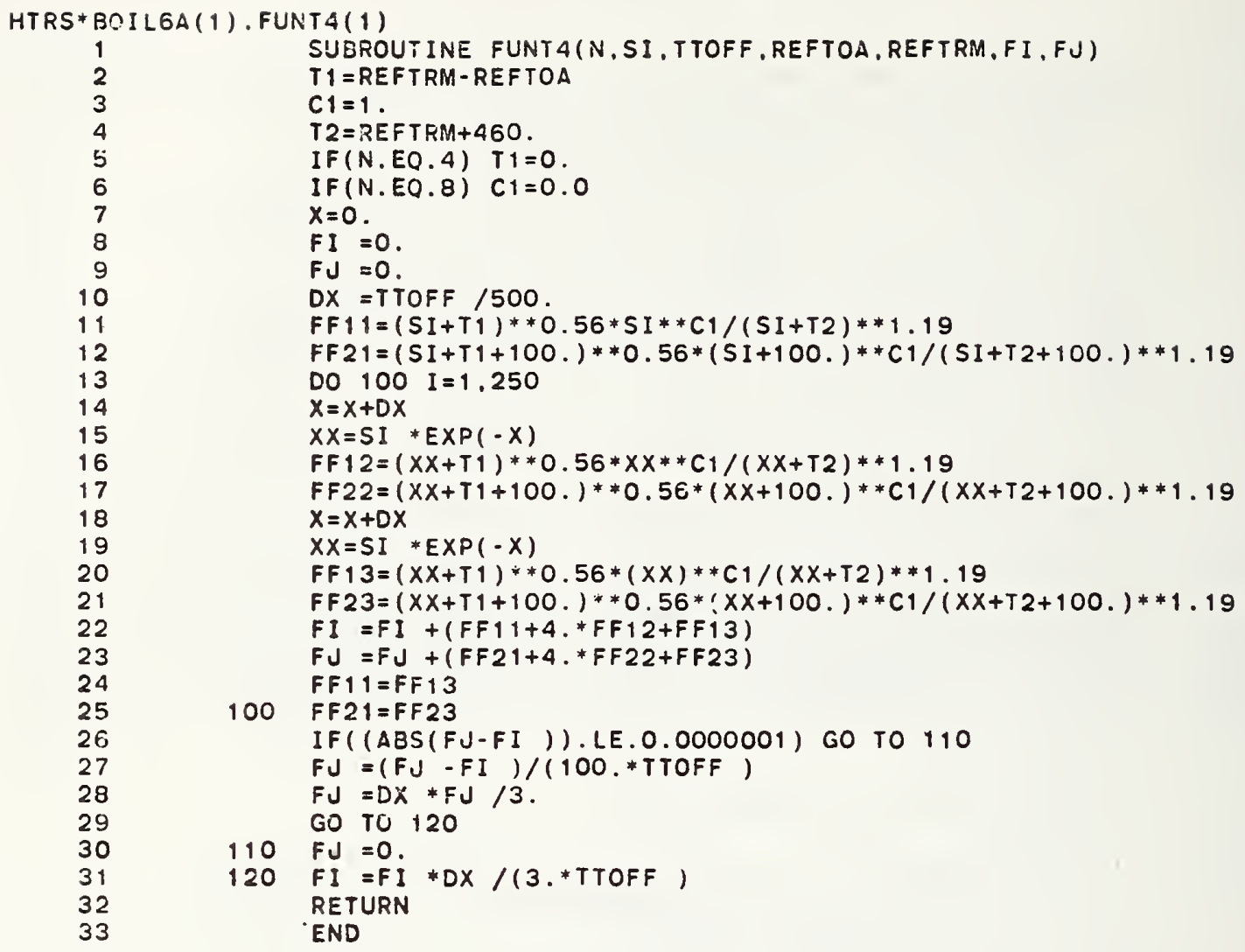


Figure C3. Input data format for FBVH

Line 1: NRUN (integer)

NRUN = number of sets of test data to be analyzed. Lines 2 through 53 should be repeated NRVN times in the stored data file/element

Line 2: TITLE

TITLE $=$ one to 80 alphanumeric characters describing the test conditions/data

Line 3: SUBTITLE

SUBTITLE = one to 80 alphanumeric characters describing the test conditions/data

Line 4: IFB, INST, ICTRL, LOSOPT (all integers)

$I F B=1$ for furnaces

$=2$ for boilers

$=3$ for vented heaters

INST $=1$ for vented heating equipment installed indoors

$=2$ for vented heating equipment installed outdoors and floor furnaces

ICTRL $=0$ for single stage controls

$=1$ for step modulating controls

$=2$ for two stage controls

LOSOPT $=0$ for analytic determination of off-cycle stack losses (method used in References 1 and 4)

$=1$ for determination of off-cycle stack losses from tracer gas technique (see Reference 6)

Line 5: NSYS, IFUEL, HHV, QP, PE, BE, XCO25

Line 6: TSSS, XCO2F, TFSS, TFON1, TFON2, TFOFF3, TFOFF4, TFOFF5

Line 7: TRA, QJ, SFR, DF, DS, Y

Measured quantities/assigned values defined in Reference 4, evaluated at maximum firing rate

Line 8: TON, TOFF, TOA

$\left.\begin{array}{l}\text { TON }=20 \mathrm{~min} \\ \text { TOFF }=20 \mathrm{~min} \\ \text { TOA }=45^{\circ} \mathrm{F}\end{array}\right\}$ For Vented Heaters

See Reference 4 for values for other types of heating equipment. 
OMIT LINES 9-11 for single stage controls $\quad($ ICTRL $=0$ )

Line 9: QINM, XCO2SM

Line 10: TSSSM, XCO2FM, TFSSM, TFON1M, TFON2M, TFOF3M, TFOF4M, TFOF5M

Line 11: TRAM, SFRM, DFM, DSM

Measured quantities/assigned values evaluated at minimum firing rate

OMIT LINES 12-53 for Analytic Determination of Off-Cycle Losses (LOSOPT $=0$ )

\section{Lines $12-31 \cdot$ CONC, TS}

CONC = measured concentration of tracer gas in sample taken from stack, PPM $\mathrm{TS}=$ measured stack gas temperature, ${ }^{\circ} \mathrm{F}$

Twenty sets of concentration and temperature measurements for a cooldown following steady state operation at maximum fire. For more details on tracer measurements see Reference 3.

Line 32: CONCI, VTTT, TROOM

CONCI = concentration of active traver gas in the tracer gas in PPM, eg., for a carbon monoxide/nitrogen tracer gas mixture consisting of 50.8 percent carbon monoxide, $\mathrm{CT}=508,000 \mathrm{PPM}$

VTTT = volumetric flow rate of tracer gas, $\mathrm{cm}^{3} / \mathrm{sec}$

TROOM = test room temperature, ${ }^{\circ} \mathrm{F}$

Values for test at maximum firing rate.

OMIT LINES 33-53 For Single Stage Controls (ICTRL = 0)

Lines 33-52: CONCM TSM

Twenty sets of concentration and temperature measurement for a cooldown following steady state operation at minimum fire.

Line 53: CONCIM, VTTTM, TROOMM

Values for test at minimum firing rate.

Figure C3 (cont) 
Figure C4. Input data form for FBVH

\begin{tabular}{|c|c|c|c|c|c|c|c|c|}
\hline & $\overline{F B I}$ & DATA & RUN \# & & & DATE & & \\
\hline LINE \# & NRUN & & & & & & & \\
\hline 1 & TIILE & & & & & & & \\
\hline 2 & 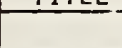 & & & & & & & \\
\hline & SUBT IT & & & & & & & \\
\hline 3 & & & & & & & & \\
\hline & IFB & INST & ICTRL & LOSOPT & & & & \\
\hline 4 & & & & & & & & \\
\hline & NSYS & IFUEL & HHV & $\overline{\text { QIN }}$ & $Q P$ & $\overline{P E}$ & $B E$ & $x \mathrm{CO} 2 \mathrm{~S}$ \\
\hline 5 & & & & & & & & \\
\hline & TSSS & $\mathrm{XCO2F}$ & TFSS & TFON] & TFON2 & IFOFF 3 & TFOFF 4 & IFOFF5 \\
\hline$\sum_{2}$ & & & & & & & & \\
\hline & TRA & Qu & SFR & $\mathrm{DF}$ & $D S$ & $\bar{Y}$ & & \\
\hline$\frac{\frac{\alpha}{2}}{2}$ & & & & & & & & \\
\hline & TON & TOFF & TOA & & & & & \\
\hline 8 & & & & & & & & \\
\hline & QINM & XC02SM & & & & & & \\
\hline 9 & & & & & & & & \\
\hline & TSSSM & $X \mathrm{CO} \mathrm{FM}$ & TFSSM & TFONIM & TFON2M & TFOF $3 \mathrm{M}$ & TFOF $4 \mathrm{M}$ & TFOF 5M \\
\hline 10 & & & & & & & & \\
\hline & IRAM & SFRM & DFM & DSM & & & & \\
\hline$\Sigma[11$ & & & & & & & & \\
\hline & TIME & CONC & TS & $\longrightarrow$ & LINE \# & TIME & CONCM & TSM \\
\hline$[12$ & $0-1$ & & & & [33 & $0-1$ & & \\
\hline 13 & $1-2$ & & & & 34 & $7-2$ & & \\
\hline 14 & $2-3$ & & & & 35 & $2-3$ & & \\
\hline 15 & $3-4$ & & & & 36 & $3-4$ & & \\
\hline 16 & $4-5$ & & & & 37 & $4-5$ & & \\
\hline 17 & $5-6$ & & & & 38 & $5-6$ & & \\
\hline 18 & $6-7$ & & & & 39 & $6-7$ & & \\
\hline 19 & $7-8$ & & & & 40 & $7-8$ & & \\
\hline 20 & $8-9$ & & & & 41 & $8-9$ & & \\
\hline 21 & $9-10$ & & & $\frac{2}{2}$ & 42 & $9-10$ & & \\
\hline 22 & $10-11$ & & & $\Xi$ & 43 & $10-11$ & & \\
\hline 23 & $11-12$ & & & $\sum_{\Sigma}$ & 44 & $11-12$ & & \\
\hline 24 & $12-13$ & & & $\frac{1}{z}$ & 45 & $12-13$ & & \\
\hline 25 & $13-14$ & & & $\bar{\Sigma}$ & 46 & $13-14$ & & \\
\hline 26 & $14-15$ & & & & 47 & $14-15$ & & \\
\hline 27 & $15-16$ & & & & 48 & $15-16$ & & \\
\hline 28 & $16-17$ & & & & 49 & $16-17$ & & \\
\hline 29 & $17-18$ & & & & 50 & $17-18$ & & \\
\hline 30 & $18-19$ & & & & 51 & $18-19$ & & \\
\hline 31 & $19-20$ & & & & 52 & $19-20$ & & \\
\hline & CONCI & VTTT & TROOM & & & CONCIM & VTTTM & Ifoolm \\
\hline 32 & - & & & & 53 & & & \\
\hline
\end{tabular}


Figure C5. Program output for a heater with step-modulating control

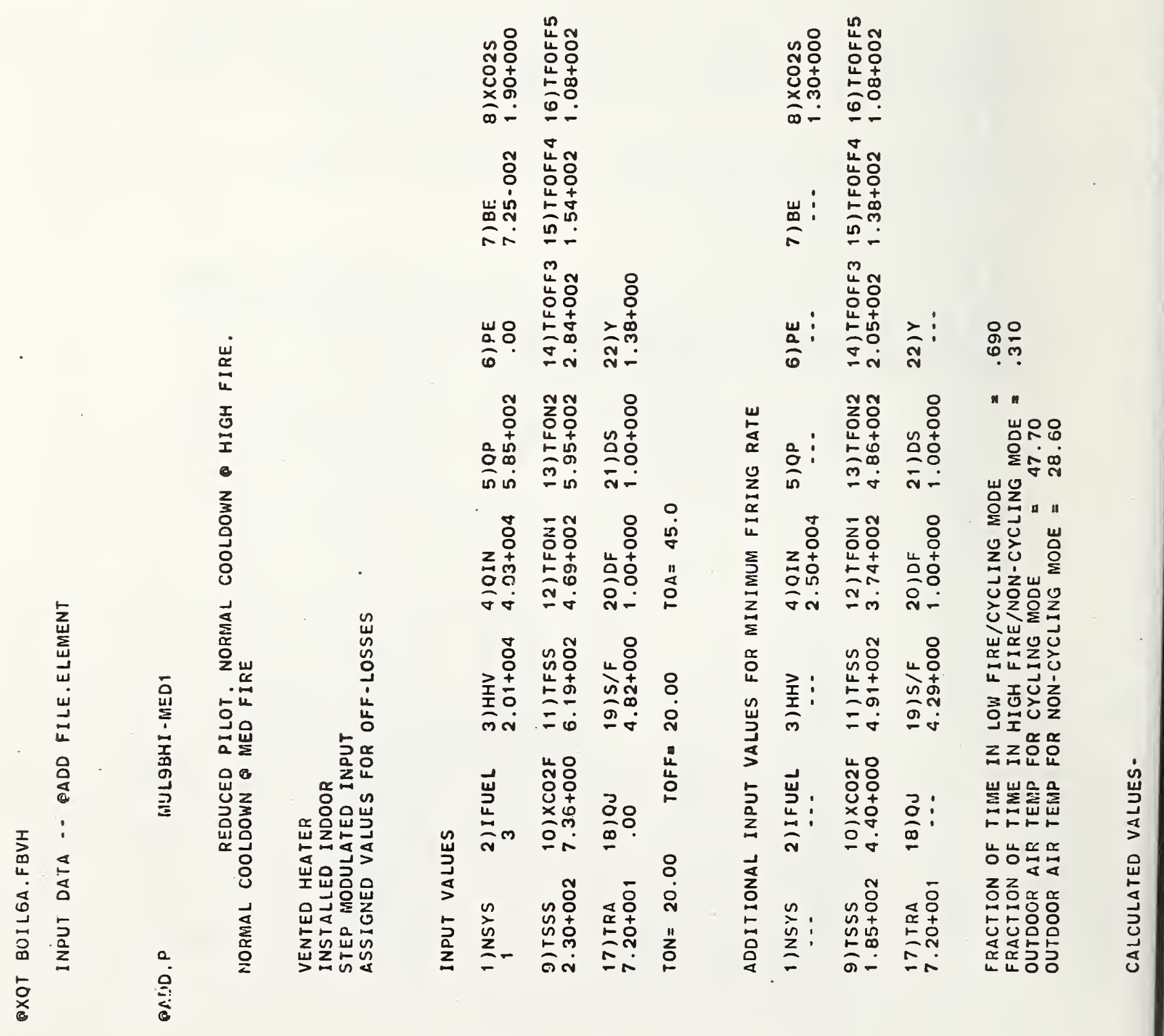




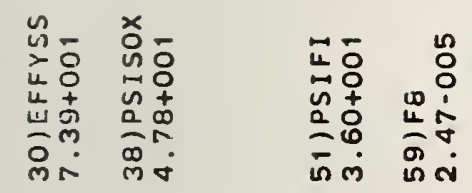

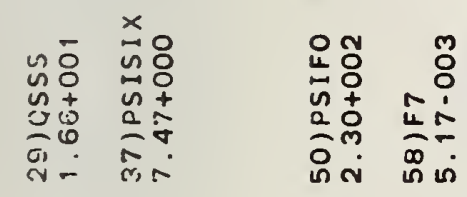

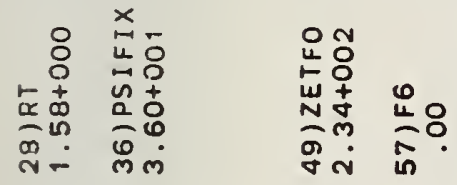

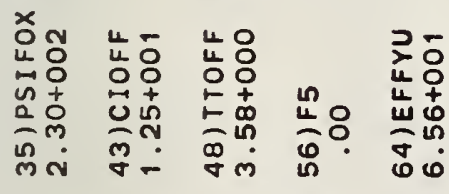

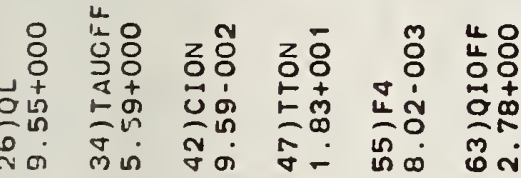

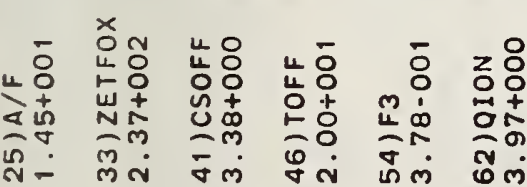

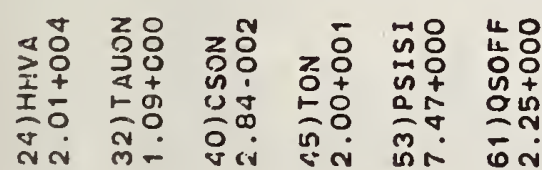

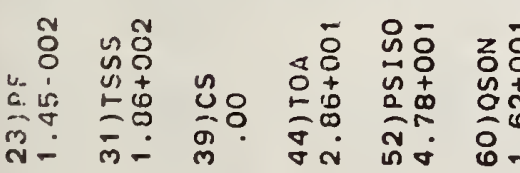

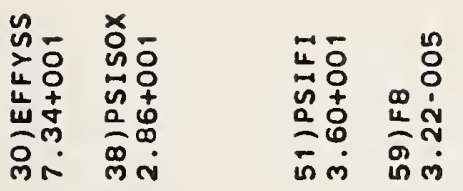

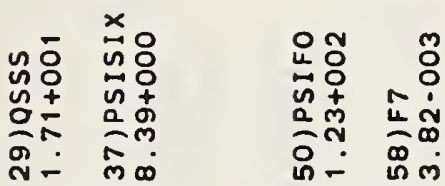

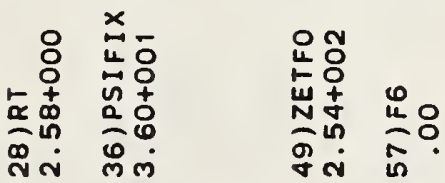

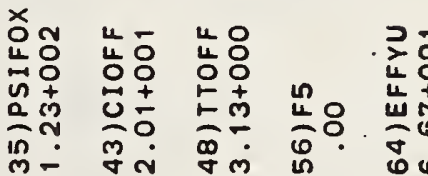

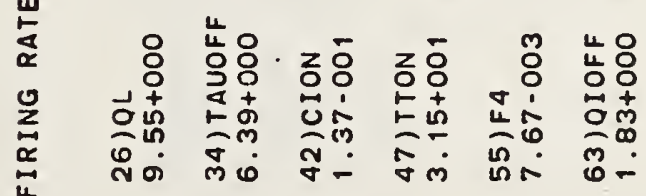

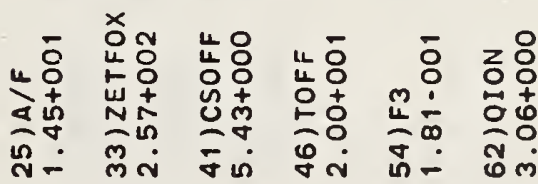

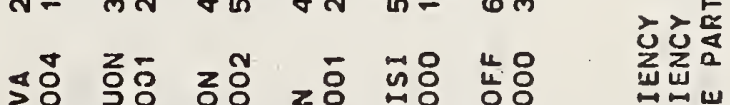

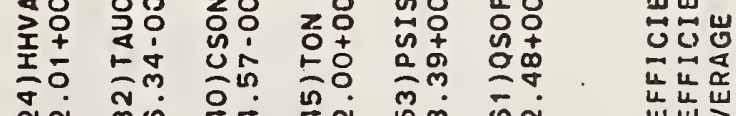

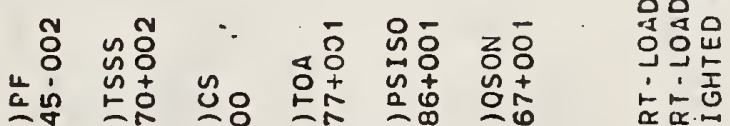

एक

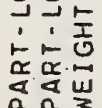

点

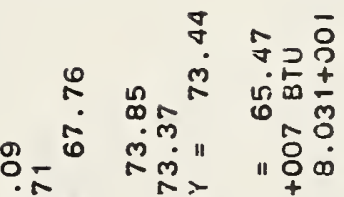

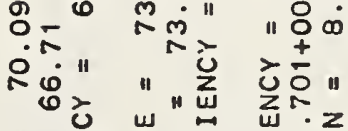

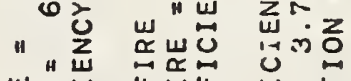

๘ँ

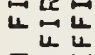

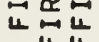
出

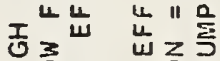
至言以 w

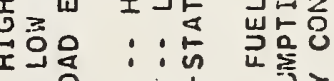

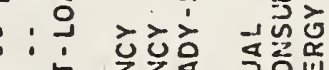

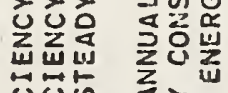

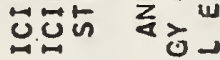

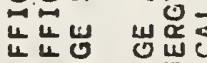

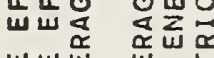

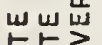
造文 文㟧 战口 证山

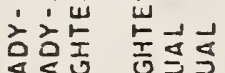

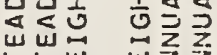

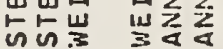


Figure C6. Program output for a heater with two-stage control

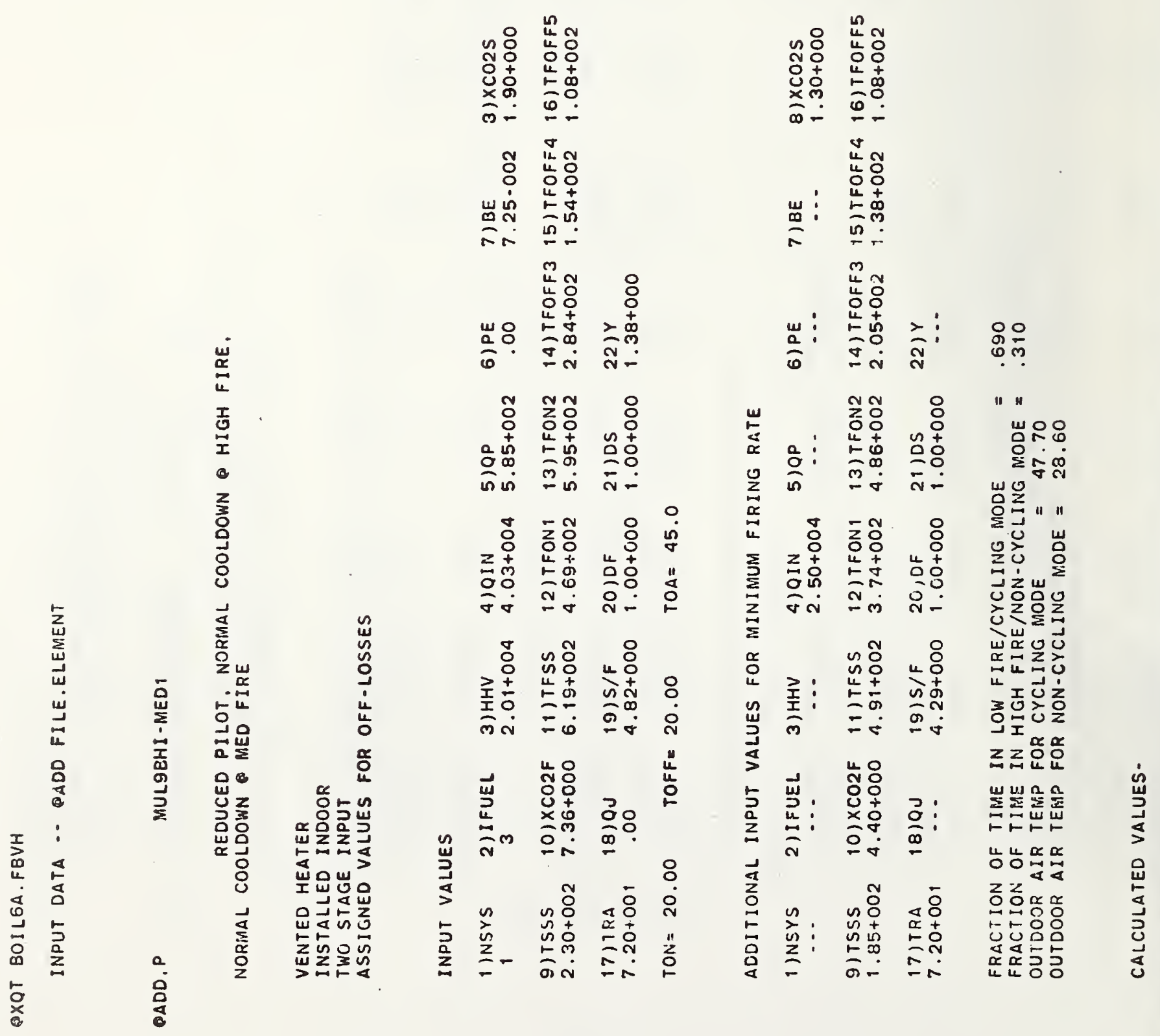




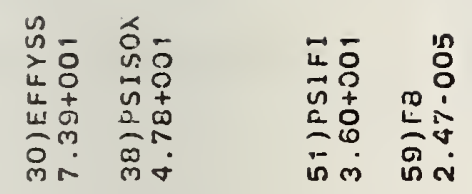

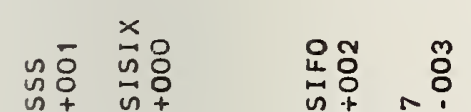

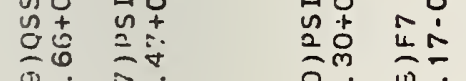

ज. in

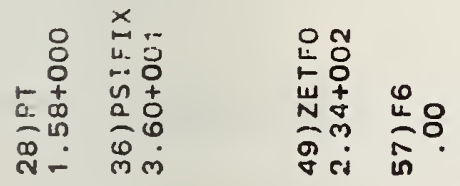

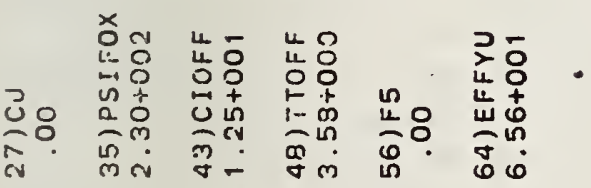

ㄴ

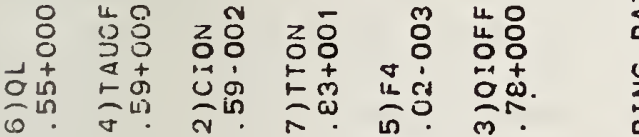

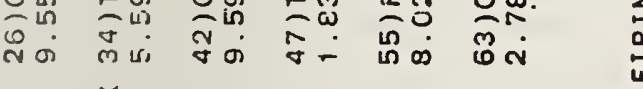

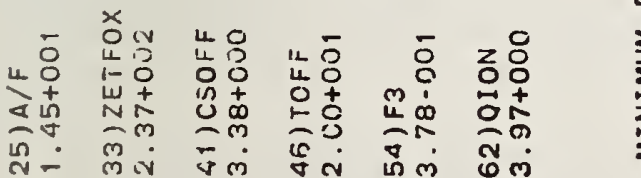

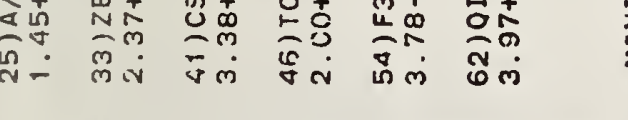

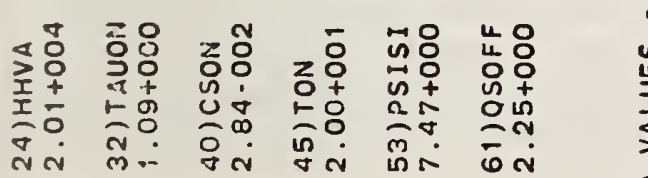

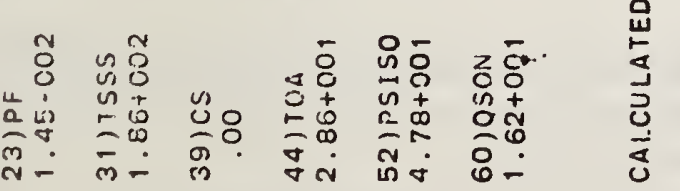

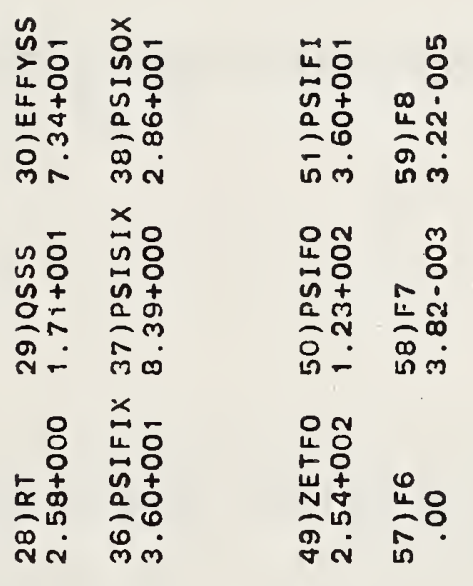

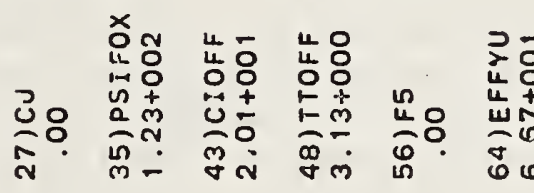

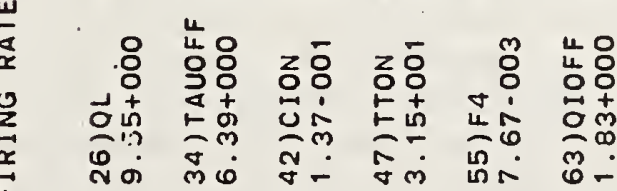

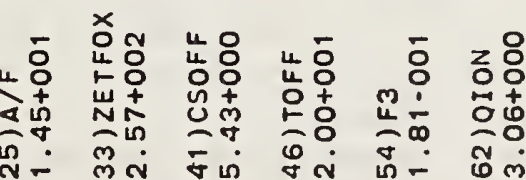

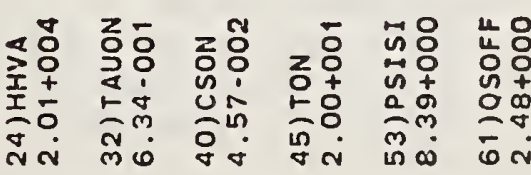

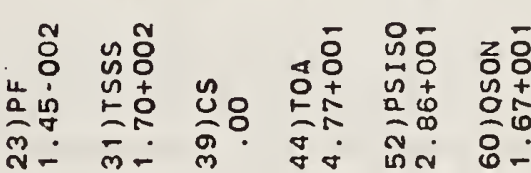

난

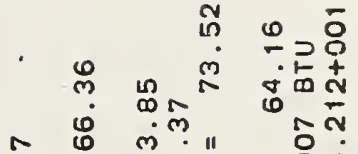
กีะ

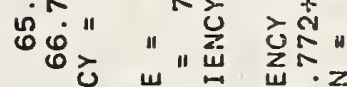

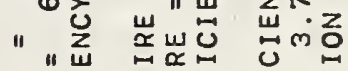

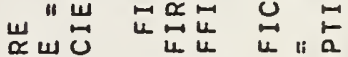

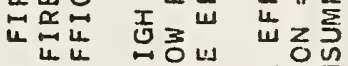

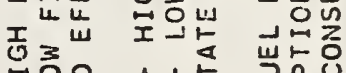

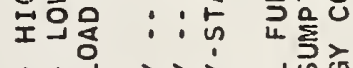

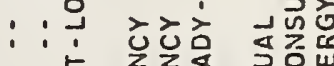

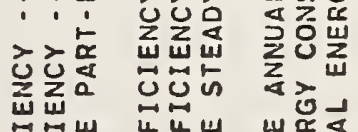

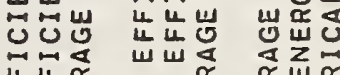
出出岳

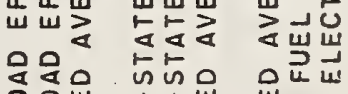

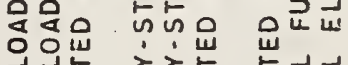
ํ. 近造通 山世

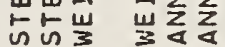


NBS-114A (REV. 2.8C)

U.S. DEPT. OF COMM.

BIBLIOGRAPHIC DATA

SHEET (See instructions)

1. PUBLICATION OR

REPORT NO.

NBSIR 82-2497

2. Performing Organ. Report Nod 3. Publication Date

4. TITLE AND SUBTITLE

A TEST METHOD AND CALCULATION PROCEDURE FOR DETERMINING ANNUAL EFFICIENCY FOR VENTED HOUSEHOLD HEATERS AND FURNACES EOUIPPED WITH MODULATING TYPE THERMOSTAT CONTROLS

5. $\operatorname{AUTHOR}(S)$

Esher Kweller and Robert Palla

6. PERFORMING ORGANIZATION (If joint or other than NBS, see instructions)

NATIONAL BUREAU OF STANDARDS

DEPARTMENT OF COMMERCE

WASHINGTON, D.C. 20234

9. SPOISSORING ORGANIZATION NAME AND COMPLETE ADORESS (Street, City, Stote, ZIP)

U.S. Department of Energy

1000 Independence Avenue

Washington, DC 20585

10. SUPPLEMENTARY NOTES

Document describes a computer program; SF-185, FIPS Software Summary, is attached.

11. ABSTRACT (A 200-word or less factual summary of most significant information. If document includes a significant bibliography or literature survey. mention it here)

As annual operating efficiency of vented heating equipment is affected by burner fuel and combustion air modulation, it is important to differentiate between the various types of controls in determining annual energy requirements. Test procedures for evaluating annual efficiency have already been developed and implemented by the Department of Energy (DoE) for furnaces with single-stage thermostat control. A modified test procedure is necessary to account for operation with fuel modulation. A revised procedure which accommodates two types of fuel modulating controls has recently been developed. Tests are conducted at reduced and maximum firing rates, and along with typical derived values from a bin analysis of weather data, the fraction of the total hours for each operating mode is obtained to calculate a weighted annual efficiency. These test methods and calculation procedures are based on and are an extension to the current DoE test procedures for the single-stage type of thermostat control of central warm air furnaces.

By using the procedures developed in the report, the energy savings impact of fuel modulating controls when combined with the use of modulated combustion air is evaluated. Energy savings from 6 percent to 20 percent were determined from the increase in efficiency with both fuel and combustion air modulation. Improved efficiency was dependent on the type of thermostat control and the minimum-to-maximum fuel input; i.e., turndown ratio.

12. KEY WORDS (Six to twelve entries; alphabetical order; capitalize only proper names; ond separate key words by semicolons) annual efficiency; household heaters and furnace test procedures; hydraulic thermostat control; modulating control gas-fueled; two-stage thermostat.

13. AVAILABILITY

X] Unlimited

For Official Distribution. Do Not Release to NTIS

Order From Superintendent of Documents, U.S. Government Printing Office, Washington, D.C. 20402.

14. NO. OF PRINTED PAGES

65

15. Price

$\$ 9.00$ 

